\title{
Update on molecular pathology and role of liquid biopsy in nonsmall cell lung cancer
}

\author{
Pamela Abdayem (1D) and David Planchard
}

Number 6 in the Series "Thoracic oncology"
Edited by Rudolf Huber and Peter Dorfmüller

Dept of Cancer Medicine, Thoracic Group, Gustave Roussy Cancer Campus, Villejuif, France.

Corresponding author: David Planchard (David.planchard@gustaveroussy.fr)

Shareable abstract (@ERSpublications)

Screening for driver alterations in patients with advanced lung adenocarcinoma and those with squamous cell carcinoma and no/little smoking history is mandatory. Liquid biopsy is evolving constantly and will definitely improve outcomes in thoracic oncology. https://bit.ly/2XjuQrD

Cite this article as: Abdayem P, Planchard D. Update on molecular pathology and role of liquid biopsy in nonsmall cell lung cancer. Eur Respir Rev 2021; 30: 200294 [DOI: 10.1183/16000617.0294-2020].

Copyright @The authors 2021

This version is distributed under the terms of the Creative Commons Attribution Non-Commercial Licence 4.0. For commercial reproduction rights and permissions contact permissions@ersnet.org

Received: 6 Sept 2020 Accepted: 26 Dec 2020

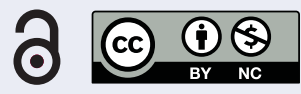

\section{Abstract}

Personalised medicine, an essential component of modern thoracic oncology, has been evolving continuously ever since the discovery of the epidermal growth factor receptor and its tyrosine kinase inhibitors. Today, screening for driver alterations in patients with advanced lung adenocarcinoma as well as those with squamous cell carcinoma and no/little history of smoking is mandatory. Multiplex molecular platforms are preferred to sequential molecular testing since they are less time- and tissue-consuming. In this review, we present the latest updates on the nine most common actionable driver alterations in nonsmall cell lung cancer. Liquid biopsy, a simple noninvasive technique that uses different analytes, mostly circulating tumour DNA, is an appealing tool that is used in thoracic oncology to identify driver alterations including resistance mutations. Additional roles are being evaluated in clinical trials and include monitoring the response to treatment, screening for lung cancer in high-risk patients and early detection of relapse in the adjuvant setting. In addition, liquid biopsy is being tested in immune-oncology as a prognostic, predictive and pharmacodynamic tool. The major limitation of plasma-based assays remains their low sensitivity when compared to tissue-based assays. Ensuring the clinical validity and utility of liquid biopsy will definitely optimise cancer care.

\section{Nonsmall cell lung cancer in the era of precision medicine}

Lung carcinogenesis is the outcome of an imbalance between oncogenes and tumour suppressor genes leading to a malignant mass of cells that acquire the phenotypic "hallmarks of cancer" [1]. The discovery of oncogene addiction led to the development of targeted therapies against driver mutations that yielded impressive response rates and survival outcomes in advanced nonsmall cell lung cancer (NSCLC), a disease with a dismal prognosis until a few years ago [2]. Our understanding of the molecular mechanisms of this disease has improved significantly with the latest advances in molecular testing, mainly with the advent of next-generation sequencing (NGS). Our ultimate goals are to classify lung tumours into groups that integrate clinical, genomic, epigenomic, transcriptomic, proteomic and metabolomic data and to determine the best diagnostic and treatment methods for each group [3]. Individualised genomic-driven management decisions have become a standard of care in NSCLC ever since the discovery of the epidermal growth factor receptor (EGFR) driver oncogene and its tyrosine kinase inhibitors (TKIs) [4]. Today, there are more than nine identified actionable driver alterations and molecular screening is mandatory in patients with nonsquamous cell carcinoma and those with squamous cell carcinoma (SCC) who are never- or light smokers. Simultaneous molecular testing (multiplex panels) is recommended rather than sequential testing with an objective to save both time and tissue. Our understanding of the molecular "code" of NSCLC at the time of initial diagnosis, progression and resistance to therapy is evolving rapidly. 
We have more diagnostic, prognostic and theragnostic molecular biomarkers than ever before and the time when every cancer patient undergoes cost-effective comprehensive molecular screening that dictates treatment is imminent [5, 6]. Moreover, the histological phenotype of NSCLC should not be underestimated, as it can predict the presence/absence of driver alterations and thus guide molecular testing, especially in the case of limited resources. In addition to having the worst prognosis among the adenocarcinoma histological subtypes, micropapillary and solid adenocarcinoma subtypes have the lowest frequency of targetable driver alterations, except for BRAF-V600E mutations, whereas sensitising EGFR mutations are most frequently found in the lepidic subtype [7]. In this review, we provide the latest updates on common oncogenic drivers in NSCLC and we focus on the latest applications of liquid biopsy in thoracic oncology.

\section{Oncogenic driver alterations in NSCLC: where do we stand?}

\section{KRAS}

KRAS mutations are the most common driver alterations in NSCLC and are almost exclusive to adenocarcinoma (ADC) [8]. They affect 25\% of patients and are associated with smoking and shorter survival $[9,10]$. Since they do not primarily overlap with EGFR, ALK, ROS1 or BRAF, they can be used to select patients who might not benefit from further molecular testing. Not all KRAS mutations are oncogenic drivers. The most common oncogenic alterations involve exons 2 and 3, with subsequent substitutions in codons 12, 13 or 61 [11]. KRAS p.G12C, the most frequent substitution detected in $41 \%$ of KRAS-mutant NSCLC, is associated with smoking, while the KRAS p.G12D mutation is usually seen in non/former light smokers [12]. KRAS-addicted tumours have a well-differentiated epithelial gene expression phenotype, whereas KRAS-independent tumours with KRAS mutation have an epithelialmesenchymal transition (EMT) phenotype. Transforming growth factor- $\beta 1$ is a cytokine that promotes EMT, thus decreasing KRAS oncogene addiction [13, 14]. Three co-mutational clusters of KRAS-mutant tumours with distinct biological behaviours were identified. TP53-mutant tumours (39\% of co-mutated tumours) have an immune-rich microenvironment with high programmed death ligand 1 (PD-L1) expression, increased tumour infiltrating lymphocytes (TILs) and immunoediting. In contrast, STK11-inactivated tumours (20\%) have a pauci-immune microenvironment with low PD-L1 expression and few TILs as well as KEAP1 mutational inactivation. Finally, the $C D K N 2 A / B$-inactivated cluster is associated with a higher incidence of TTF1-negative ADC, mucinous histology and decreased mTORC1 signalling $[15,16]$. In addition, KRAS mutations are detected in other oncogene-addicted tumours (MET, $E G F R, B R A F$ and $A L K)$ when they develop resistance to TKIs [17]. Pre-clinical and clinical studies yielded conflicting results regarding the predictive role of KRAS mutations in chemotherapy outcomes [18, 19]. Alternatively, according to retrospective data from ImmunoTarget, a global multicentre registry, KRAS mutations were associated with an increased response to immunotherapy in comparison to other drivers [20]. KRAS-mutant NSCLC usually harbours a higher tumour mutational burden (TMB), thus explaining the increased response to immunotherapy [21]. In addition, as mentioned previously, TP53 co-mutated tumours are immunogenic and show a remarkable sensitivity to immune checkpoint inhibitors (ICIs), whereas STK11 co-mutated "cold" tumours have impaired immunosurveillance and primary resistance to these agents [21]. Despite the efforts deployed, KRAS remains a frustrating therapeutic target due to the absence of a binding pocket in the KRAS protein and its high affinity towards the abundance of cellular guanosine triphosphate [22]. Selective novel covalent direct inhibitors of the KRAS G12C mutation such as sotorasib (AMG510) and adagrasib (MRTX849) are currently being investigated and results are encouraging [22]. In contrast to former nonspecific inhibitors of KRAS, selective KRAS G12C inhibitors seem to be well tolerated, since the G12C substitution does not exist in normal tissues and thus there is no risk of off-target toxicity [12]. Results from the phase II cohort of the CodeBreak 100 study of sotorasib (AMG510, 960 mg orally, once daily) in 126 pre-treated NSCLC patients with KRAS G12C mutations showed a confirmed objective response rate (ORR) of $37.1 \%$, a disease-control rate (DCR) of $80.6 \%$, a median duration of response (mDOR) of 10.0 months and a median progression-free survival (mPFS) of 6.8 months. Most treatmentrelated adverse events were mild to moderate (grade 1 or 2) including diarrhoea (31\%), nausea (19\%) and increased alanine and aspartate aminotransferases (15.1\% each) [23]. Sotorasib was granted breakthrough therapy designation by the US Food and Drug Administration (FDA) and China for patients with pre-treated KRAS G12C-mutated NSCLC. CodeBreak 200, a phase III randomised study comparing sotorasib to docetaxel in patients with KRAS G12C-mutated NSCLC is currently underway (NCT04303780) [24]. Adagrasib achieved an ORR of 45.1\%, in 51 pre-treated KRAS G12C-mutant lung cancer patients in the pooled phase I/Ib and II KRYSTAL-1 study [25]. JNJ-746999157 is another direct G12C inhibitor that is currently being tested in a phase I trial (NCT04006301) [26]. Unlike immune checkpoint inhibitors, KRAS inhibitors are active in patients with STK11 co-mutated tumours [23, 25]. In addition, they may "heat" KRAS-mutated cold tumours by increasing T-cell infiltration, antigen presentation and interferon response, while decreasing monocyte and neutrophil recruitment [27]. Adaptive resistance to KRAS inhibitors seems to result from the increased synthesis, via EGFR and aurora kinase A signalling, of a new KRAS G12C protein 
that is less susceptible to inhibition [28]. Novel combinations with other agents may help overcome resistance to KRAS inhibitors.

\section{EGFR}

Activating somatic mutations in the tyrosine-kinase (TK) domain of EGFR were first described in 2004 [29]. They mostly affect exons 18 to 21 of the TK domain and consist mainly of short in-frame deletions of exon 19 clustered around the amino-acid residues $747-750$ (45\% of cases) in addition to a specific exon 21 missense mutation (L848R) (40\% of cases) [29, 30]. Other less-common sensitising EGFR mutations (10\% of cases) include exon 19 insertions, p.L861Q, p.G719X and p.S768I [31]. Sensitising EGFR mutations occur in $30-40 \%$ and $10-12 \%$ of Asian and non-Asian patients, respectively [32, 33]. They are frequently associated with ADC, female sex and never-smoker status [33]. They can occur in adenosquamous carcinoma, which is difficult to distinguish from pure SCC on small biopsies. Their occurrence in pure SCC is rare [34]. Sensitising EGFR mutations, ALK or ROS1 fusions, RET rearrangements, BRAF mutations and MET exon 14 skipping mutations are usually mutually exclusive [35]. First-generation TKIs gefitinib and erlotinib and second-generation afatinib achieved improved response rates and PFS time compared to standard chemotherapy in first-line treatment of advanced NSCLC with sensitising EGFR mutations [36-40]. None of the aforementioned randomised phase III studies demonstrated a benefit in overall survival with first- or second-generation TKIs, probably due to high crossover rates. Dacomitinib represents another alluring treatment option following the results of the ARCHER 1050 phase III study comparing dacomitinib to gefitinib (mPFS 14.7 versus 9.2 months, median overall survival (mOS) 34.1 versus 27.0 months) [41]. Osimertinib, a third-generation EGFR TKI with potent central nervous system (CNS) activity is currently the preferred first-line treatment in EGFR mutation-positive patients with advanced NSCLC following the results of the FLAURA trial (mPFS 18.9 versus 10.2 months with gefitinib or erlotinib, mOS 38.6 versus 31.8 months) [42]. Moreover, impressive results from the first interim analysis of the phase III ADAURA study of adjuvant osimertinib in early-stage (IB to IIIA) EGFR-mutant nonsquamous NSCLC were reported at the American Society of Clinical Oncology virtual meeting in 2020. Osimertinib versus placebo improved disease-free survival by $79 \%$ and $83 \%$ in the overall study population and in stage II to IIIA patients, respectively [43]. Other TKIs, such as poziotinib (NCT03318939) and AP32788 (NCT02716116), are being tested in patients with exon 20 insertions in EGFR and HER2, which confer natural resistance to existing EGFR TKIs. The combination of EGFR TKIs with antiangiogenic agents, namely bevacizumab and ramucirumab, improved PFS when compared to first-generation EGFR TKI monotherapy. While the addition of bevacizumab did not result in a significant increase in overall survival times in the final analysis of the NEJ026 trial, overall-survival data regarding the addition of ramucirumab to erlotinib remain immature [44-46]. Recently, results of the ETOP BOOSTER phase II randomised trial of second-line osimertinib and bevacizumab versus osimertinib monotherapy in EGFR T790M-mutated NSCLC did not show any PFS advantage of the combination therapy over osimertinib alone [47]. In contrast, the addition of pemetrexed and carboplatin to gefitinib versus gefitinib monotherapy significantly prolonged PFS and OS, but increased toxicity in a phase III randomised study in treatment-naïve patients with EGFR-mutated advanced NSCLC [48]. FLAURA2 is a currently recruiting phase III study of osimertinib with or without chemotherapy as first-line treatment in EGFR-mutated NSCLC (NCT04035486) [49]. Despite the impressive outcomes mentioned so far, patients eventually progress after front-line EGFR TKI treatment. EGFR p.Thr790Met (T790M) mutation was found in $60 \%$ of the patients who progressed after erlotinib, gefinitib or afatinib [50, 51]. The AURA3 phase III study showed improved ORR (71\% versus 31\%), mPFS time (10.2 versus 4.4 months) and numerical mOS time (26.8 versus 22.5 months, mostly due to patient crossover) in patients with acquired EGFR T790M mutation after first-line EGFR TKI therapy who received osimertinib in comparison to pemetrexed-platinum chemotherapy [52]. Primary T790M mutation is rare and possibly constitutional. TKI-naïve patients with T790M mutation should have genetic counselling in search for a familial predisposition to lung cancer [53]. Other, less common mechanisms of acquired resistance to first-line erlotinib, gefitinib and afatinib include the following.

1) Histological transformation to small-cell lung cancer (5\%) [54]. In a retrospective analysis by MARCouX et al. [55], the transformation occurred at an average of 17.8 months after diagnosis and genomic profiling showed mutations in Rb1, TP53 and PIK3CA.

2) Increased activity of additional kinases due to MET (5\%), ERBB2 (10\%) or extracellular signal-regulated kinase (ERK) amplification, mutation of PIK3CA (which encodes the PI3 K p110 $\alpha$ subunit) (2\%) or overexpression of AXL kinase [56-58].

3) Modifications in splicing and deletion of the pro-apoptotic BCL-2-homology domain (BH3) due to a common BIM (also known as BCL2L11) polymorphism that probably affects intrinsic resistance to EGFR inhibitors, thus highlighting the complexity of possible resistance mechanisms [59, 60].

4) Other alterations such as PTEN downregulation, CRKL amplification, high-level HGF expression, FAS-NFאB pathway activation and EMT [61]. Of interest, EGFR mutation-positive patients with 


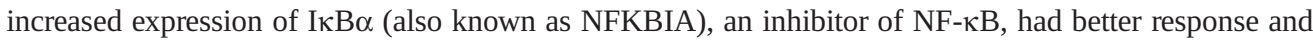
survival outcomes [62].

Using paired plasma samples analysed using NGS, RAMALINGAM et al. [63] described the main resistance mechanisms to osimertinib in 91 patients with detectable plasma EGFR mutations in the FLAURA trial. Acquired EGFR T790M mutation was not found in the osimertinib arm, and the most common acquired resistance mechanisms were off-target MET amplification (15\% of patients), on-target EGFR C797S mutation (on-target, 7\%), downstream PIK3CA, BRAF V600E and KRAS G12D/C and A146 T mutations (7\%, 3\% and 3\%, respectively) as well as off-target HER2 amplification (2\%). A retrospective tissue analysis using NGS in 62 patients treated with osimertinib in the first- or later-line settings identified the following resistance mechanisms that were influenced by time on osimertinib treatment, initial EGFR mutation and line of therapy.

1) Histological transformation to SCC (most frequent), small cell carcinoma or pleomorphic carcinoma ( $15 \%$ and $14 \%$ of patients treated in the first- and later-line settings, respectively) [64].

2) Off-target genetic resistance ( $19 \%$ and $24 \%$ of patients in first- and later-line settings). MET amplification (7\%), KRAS mutation (4\%), BRAF (4\%) and RET fusions (4\%) were the most commonly identified off-target resistance mechanisms in the first-line setting [64].

3) On-target EGFR G724S mutation (4\%) and EGFR amplification in the first-line setting (4\%). On-target EGFR C797X mutation (29\%), EGFR amplification (6\%) and EGFR SV758IL compound mutation (3\%) in the later-line setting [64].

Amivantamab (JNJ-61186372) is a fully human bispecific antibody that targets EGFR and MET. It demonstrated clinical activity across diverse EGFR-mutated NSCLC (exon 21 L858R, exon 19 deletion, exon 18 G719A, exon 20 insertion, T790M, C797S, coexistent MET amplification) [65]. It was granted FDA breakthrough therapy designation for EGFR-mutant exon 20 insertion NSCLC post-chemotherapy. Moreover, results from the CHRYSALIS phase I study of the combination of amivantamab with lazertinib, a third-generation EGFR TKI in osimertinib-resistant, chemo-naïve patients showed an ORR of 36\% and a clinical benefit rate of $60 \%$ [66]. In the TATTON multi-cohort study, the addition of savolitinib, a potent selective MET inhibitor, to osimertinib, in TKI pre-treated patients with EGFR-mutant and MET-amplified/ overexpressed (by fluorescent in situ hybridisation, immunohistochemistry (IHC) or NGS) advanced NSCLC, showed impressive ORRs of 33\%, 65\% and 62\% in cohorts B1 (prior treatment with thirdgeneration EGFR TKI), B2 (savolitinib 600/300 mg per weight-based dosing, no prior treatment with third-generation EGFR TKI and absence of T790M mutation) and D (savolitinib $300 \mathrm{mg}$, no prior treatment with third-generation EGFR TKI and absence of T790M mutation), respectively. Of note, exposure to prior TKIs was heterogenous and it was unclear whether the response to treatment was consistent across all "MET-positive” patients (FISH versus IHC versus NGS) [67]. Finally, patritumab deruxtecan (U3-1402), a novel antibody drug conjugate designed to target HER3 expression in EGFRmutant NSCLC, demonstrated antitumour activity with a response rate of $25 \%$ a DCR of $70 \%$ and a mDOR of 6.9 months. Efficacy was observed in patients with various mechanisms of EGFR TKI resistance, including EGFR C797S, MET amplification, HER2 mutation, BRAF fusion and PIK3CA mutation [68].

ALK

Anaplastic lymphoma kinase $(A L K)$ gene rearrangements occur in $5 \%$ of patients with NSCLC, predominantly in ADC and in never-/light smokers [69, 70]. Compared with EGFR-mutant patients, those with $A L K$ rearrangements are younger and more likely to be male [70]. Echinoderm microtubule-associated protein-like 4 (EML4)-ALK fusion gene resulting from an inversion of the short strand of chromosome 2 was first observed in lung cancer in 2007, and many other $A L K$ fusions, differing by the N-terminal gene fusion partner, have since been identified in lung and other cancers [71]. EMLA4-ALK is an abnormal fusion gene that encodes a cytoplasmic chimeric protein with constitutive kinase activity. Crizotinib achieved improved outcomes in front-line treatment of advanced NSCLC with ALK fusions and became standard of care (mPFS 10.9 months versus 7 months with chemotherapy; mOS not reached versus 47.5 months with chemotherapy) [72, 73]. Ceritinib, alectinib and brigatinib may be used after first-line crizotinib and ceritinib or alectinib may also be used in the first-line setting [74, 75]. The updated results of the ALEX study which compared alectinib to crizotinib in TKI-naïve patients with $A L K$-rearranged NSCLC showed a higher 5-year overall survival rate (62.5\% versus $45.5 \%$; mOS data are still immature) in addition to a longer mPFS time (34.8 versus 10.9 months), a higher CNS ORR (59\% versus 26\%) and a longer time to CNS progression [74, 76]. Similarly, in the ALESIA randomised phase III trial which included 187 treatment-naive Asian patients with advanced $A L K$-rearranged NSCLC, alectinib was significantly superior to crizotinib in terms of mPFS time [77]. Moreover, brigatinib (ALTA-1L trial), as well as ensartinib (EXALT-3 trial), a potent newer-generation ALK inhibitor, achieved better mPFS times 
in comparison with crizotinib in first-line treatment of advanced NSCLC with ALK fusions (mPFS 24 versus 11 months and 25.8 versus 12.7 months, respectively) [78, 79]. The CROWN phase III study demonstrated higher ORR (76\% versus 58\%), higher intracranial response rate (82\% versus 23\%), and longer mPFS (not reached versus 9.3 months) with lorlatinib, a third-generation brain-penetrant $A L K$ and ROS1 inhibitor compared with crizotinib in TKI-naïve patients with ALK-positive advanced NSCLC [80]. As with other oncogene-addicted lung tumours, patients eventually develop resistance to $A L K$ TKIs through the following mechanisms.

1) Secondary $A L K$ mutations, found in one third of crizotinib-resistant tumours [35]. The most frequent mutations in this case are L1196M and G1269A [81, 82]. Other less frequent mutations include $L 1152 R$, 1151 T-ins, C1156Y, I1171 T, F1174 L, G1202R and S1206Y [83]. Alectinib, ceritinib and brigatinib are able to overcome the majority of ALK-resistant mutations (L1196M, G1269A and F1174L) acquired with crizotinib. I1171 T/N/S and G1202R are observed in tumours resistant to alectinib and F1174C/V and $G 1202 R$ are found in those resistant to ceritinib [83]. Lorlatinib is particularly active against the solvent front mutation G1202R [84]. A phase II study of lorlatinib in ALK-positive NSCLC resulted in an ORR of $72.90 \%$ in patients who had only received previous crizotinib, $42.9 \%$ in patients treated with one previous non-crizotinib ALK TKI (EXP3B) and 39.6\% in patients treated with two or more previous ALK TKIs [85]. TPX-0131 is a next-generation $A L K$ inhibitor that was shown in cell proliferation assays to be active against the G1202R mutation (more than 100-fold more potent than lorlatinib) and against compound mutations of both gatekeeper and solvent front mutations (L1196M/G1202R) that are refractory to lorlatinib [86].

2) Activation of "bypass" pathways, present in 40\% of crizotinib-resistant tumours. Activated pathways include EGFR, cKIT, IGF1R and Src. Alectinib resistance mechanisms include c-MET amplification while ceritinib-resistant tumours harbour $M E K$-activating mutations [83].

3) Amplification of the $A L K$ fusion gene, found in $9 \%$ of crizotinib-resistant tumours [35, 87].

4) Other mechanisms including EMT, apoptosis regulation and epigenetic modifications, as well as transformation to small-cell lung carcinoma [83, 87-89].

\section{ROS1}

ROS proto-oncogene 1 (ROS1) rearrangements were first described in NSCLC in 2007 [90]. They lead to a fusion of a ROS1 TK domain with a partner gene (several options, with CD74-ROS1 fusion being the most prevalent) with subsequent activation of the ROS1 kinase leading to tumour proliferation and survival through downstream signalling via SHP-1/SHP-2, JAK/STAT, PI3 K/AKT/MTOR and mitogen-activated protein kinase (MAPK)/ERK pathways [90, 91]. ROS1 fusions affect 1-2\% of patients with NSCLC [92]. There is a significant homology between $A L K$ and ROS1 TK domains including the binding site for crizotinib [93]. Similar to $A L K$, ROS1 fusions occur mostly in patients with ADC histology who are nonsmokers or former light smokers. However, in contrast to $A L K$, ROS1 fusions are associated with lower rates of extrathoracic and intracranial metastases at the time of diagnosis, as well as lower cumulative incidence of intracranial metastases [94]. Crizotinib was granted FDA approval in 2016 for treatment of advanced NSCLC with ROS1 rearrangement following the results of the PROFILE 1001 phase I study [95]. Updated results showed an ORR of $72 \%$, a mDOR of 24.7 months, a mPFS of 19.3 months and a mOS of 51.4 months [96]. In a Korean phase 2 study, Lim et al. [97] administered ceritinib to 32 patients with ROS1 rearrangement, 30 of whom were crizotinib-naïve. ORR was 62\% (the two patients who had previously received crizotinib had no clinical response), mDOR was 21.0 months, median PFS was 9.3 months for all patients and 19.3 months for crizotinib-naïve patients and mOS was 24 months. Resistance to crizotinib is inevitable and occurs through two main mechanisms, as follows.

1) On-target mutations of the TK domain of ROS1 which affect crizotinib binding [94, 98]. The most common mutation is ROS1-G2032R (41\%). Other mutations include D2033N (6\%), S1986Y/F (6\%), gatekeeper L2026M and L1951R [94]. Lorlatinib has in vitro activity against most known ROS1 resistance mutations such as ROS1-D2033N, S1986Y/F and L2026M mutations. Its efficacy against ROS1-G2032R remains limited [90]. In contrast, repotrectinib, a next-generation ALK/ROS1/TRKA-C inhibitor with higher potency against ROS1 than crizotinib, has shown efficacy against the latter mutation [99].

2) Off-target resistance mechanisms that include activation of bypass signalling pathways such as EGFR, RAS and KIT, and phenotypic changes such as EMT [94, 98].

In an open-label phase I/II trial, 69 patients with ROS1-positive NSCLC were treated with lorlatinib. TKI-naïve patients $(n=13 ; 30 \%)$ had an ORR of 62\%, an intracranial response rate of 64\%, mDOR of 19.6 months and mPFS of 21 months. Among patients who had previously received crizotinib, ORR was 35\%, intracranial response rate was 53\% and mPFS was 8.5 months [100]. In an integrated analysis of 3 phase I/II studies (ALKA-372-001, STARTRK-1 and STARTRK-2) with a total of 53 ROS1-positive TKI-naïve 
patients, entrectinib, a ROS1, TRK and ALK TKI, achieved an ORR of 77.4\%, a mPFS of 19 months, a mDOR of 24.6 months and an intracranial ORR of 55\% [101]. TRIDENT-1 is an open-label multicentre phase I/II study of repotrectinib (TPX-0005) in patients with ROS1 or NTRK fusion-positive advanced NSCLC. Preliminary results from the phase 2 expansion 1 (EXP-1) cohort of 55 TKI-naïve ROS1-positive patients (20\% had received prior chemotherapy) showed an ORR of 93\% (in 15 evaluable patients at data cut-off on 31 December 2020). When pooled with data from seven patients treated in phase 1, the confirmed ORR was 91\%. Based on these results, repotrectinib was granted FDA breakthrough therapy designation as treatment for TKI-naive ROS1-positive advanced NSCLC. In addition, repotrectinib achieved an ORR of $40 \%$ in five patients who were pre-treated with one TKI and chemotherapy (EXP-2 cohort) and in five other patients who were pre-treated with two TKIs and no chemotherapy (EXP-3). Finally, ORR was $67 \%$ in six patients who were previously treated with one TKI and no chemotherapy (EXP-4). All patients with ROS1 G2032R mutation had tumour regression (confirmed ORR of 40\%) [102, 103]. This trial is still recruiting [104]. An updated pooled analysis of US and Japan phase 1 studies of taletrectinib, an oral, potent selective ROS1 and pan-NTRK TKI with pre-clinical activity against ROS1 G2032R solvent-front mutation, reported an ORR of 66.7\%, 33.3\% and 33.3\% among ROS1 TKI-naïve patients $(n=9)$, crizotinib-pre-treated patients $(n=6)$ and patients pre-treated with two previous TKIs $(n=3)$, respectively [105]. In the ImmunoTarget cohort, ROS1-positive tumours had the highest median PD-L1 expression among other oncogene-addicted NSCLC tumours; however, no tumour response to ICIs was reported in patients from the ALK/ROS1/RET group despite PD-L1 positivity [20].

\section{$B R A F$}

$B R A F$ is a serine/threonine protein kinase whose mutations favour tumorigenesis by activating the MAPK signalling pathway. BRAF V600E is the most common BRAF mutation across all tumour types; however, in lung ADC it occurs at the same rate as other BRAF mutations (1-2\% of patients) [106-108]. Unlike patients with EGFR or $A L K$ alterations, those with $B R A F$ mutations are more likely to be current or former smokers [107]. BRAF mutations act as an alternative oncogenic driver in NSCLC and do not overlap with EGFR mutations, ALK/ROS1/RET rearrangements, or MET exon 14 skipping mutations [108, 109]. They are almost restricted to non-mucinous ADC histological subtype [110]. In a basket trial, vemurafenib, a selective BRAF V600 inhibitor achieved a response rate of $42 \%$, a mPFS of 7.3 months and an unreached mOS in pre-treated NSCLC patients (20 patients) [111]. Secondary resistance mechanisms to BRAF inhibitors include 1) reactivation of ERK signalling through the MAPK pathway (most common resistance mechanism) which can take place upstream or downstream of BRAF kinase. Mechanisms include BRAF splice variants (16\%), BRAF gene amplification (13\%), NRAS/KRAS (20\%) or MEK1/2 mutations (7\%) that induce a BRAF-independent reactivation of ERK signalling [112, 113]; and 2) bypass of the MAPK pathway through activation of other pathways such as PI3K-AKT (through activating mutations in $A K T$ and PTEN loss of function) [113].

The combination of dabrafenib (another BRAF V600E inhibitor) and trametinib (a MEK1-2 inhibitor) results in dual inhibition of the MAPK pathway thus overcoming the ERK escape mechanism. In the second-line setting in advanced BRAF-mutated NSCLC, dabrafenib and trametinib achieved an ORR of 66.7\%, mPFS of 10.9 months and mOS of 18.2 months [108]. As front-line treatment, the same combination yielded an ORR of 64\%, mPFS of 10.2 months, mOS of 24.6 months and mDOR of 10.4 months according to a phase II study by PLANCHARD et al. [114]. Interestingly, data from the ImmunoTarget registry show that patients with BRAF mutations who received ICIs had higher response rates when compared to patients with other driver mutations (except for KRAS). Smoking had a positive impact on PFS. More specific studies are needed [20].

\section{MET}

$C-M E T$ is a hepatocyte growth factor TK receptor that promotes cell survival and proliferation. MET exon 14 skipping mutations, MET gene copy number gain or amplification and MET protein overexpression represent the main oncogenic driver alterations of $M E T$ and do not overlap with other oncogenic drivers in NSCLC $[115,116]$. They occur in 3-4\% of patients with lung ADC and 1-2\% of patients with other NSCLC subtypes. MET exon 14 skipping mutations and MET amplification may coexist $[117,118]$. MET amplification occurs as a primary driver event or as a resistance mechanism to EGFR TKI therapy. MET exon 14 skipping mutations result in impaired MET ubiquitination, decreased MET turnover, and increased downstream signalling [119]. Patients with MET exon 14 skipping mutations (3-4\% of NSCLC patients) were found to be significantly older than patients with EGFR or KRAS mutations and were more likely to be female and nonsmokers $[115,120]$. In addition, these mutations are more frequent in adenocarcinoma and sarcomatoid carcinoma histological subtypes. Crizotinib and cabozantinib are effective in patients with MET abnormalities [118, 121]. Newer therapeutic candidates include tepotinib, capmatinib and savolitinib, three selective c-MET TKIs with encouraging phase Ib/II results that are now being tested in combination 
with EGFR TKIs in EGFR TKI-resistant NSCLC [122]. The VISION phase II study of tepotinib in 152 patients with advanced NSCLC (first- and later lines) with MET exon 14 skipping mutations yielded a response rate of $46 \%$ by independent review with a mDOR of 11.1 months (in the combined tissue and liquid biopsy group) regardless of the number of previous treatment lines [119]. In the phase II GEOMETRY mono-1 study of capmatinib in patients with MET exon 14 mutations, the response rate was 41\% and 68\% among 69 previously treated and 28 treatment-naïve patients, respectively. mPFS was 5.42 and 9.13 months, respectively [123]. In addition, the authors reported an ORR of $40 \%$ and $29 \%$ in TKInaïve and TKI pre-treated patients with MET amplification who received capmatinib [124].

RECONDo et al. [125] studied mechanisms of acquired resistance to MET TKIs using plasma and tissue NGS. On-target acquired mechanisms of resistance (35\% of cases) included single and polyclonal MET kinase domain mutations in codons H1094, G1163, L1195, D1228 and Y1230, and high levels of amplification of the MET exon 14-mutant allele [125]. Glesatinib, a spectrum-selective MET inhibitor with a distinct mechanism of target inhibition can overcome resistance to type I MET inhibitors [126]. Offtarget mechanisms of resistance (45\% of cases) included KRAS mutations and amplifications in KRAS, EGFR, HER3 and BRAF [125].

\section{RET}

Rearrangements between the RET gene and other domains (mainly KIF5B and CCDC6) lead to an overexpression of the RET protein, a TK receptor that influences cell proliferation and differentiation. RET rearrangements occur in 1-2\% of patients with NSCLC, mainly in ADC, and are independent of smoking status [127-129]. They are usually mutually exclusive with other oncogenic drivers, although some studies describe a possible overlap of RET rearrangements with EGFR or KRAS mutations [130]. Prior to the development of selective $R E T$-inhibitors, response rates and survival outcomes of patients with RET-rearranged NSCLC who received multikinase inhibitors such as cabozantinib, vandetanib, sunitinib, sorafenib, alectinib, lenvatinib, nindetanib, ponatinib and regorafenib were heterogenous (small biased studies) and mostly disappointing in comparison to those achieved with selective TKIs in other oncogene-driven NSCLC tumours (ORR 16-47\% and mPFS 2.3-7.3 months) [128, 131, 132]. In contrast, selpercatinib (formerly LOXO-292) and pralsetinib (formerly BLU-667) selectively block RET, thus avoiding other targets and limiting side-effects. Based on data from the LIBRETTO-001 phase I/II trial that resulted in ORRs of $70 \%$ and $90 \%$ in 105 patients previously treated with platinum-based chemotherapy and 39 treatment-naïve patients, respectively, selpercatinib obtained FDA breakthrough designation for the treatment of RET fusion-positive NSCLC in August 2018 [133]. In the phase I/II ARROW trial, pralsetinib yielded an ORR of 65\% in 116 patients (first- or later line settings) and $73 \%$ in 26 treatment-naïve patients [134]. AcceleRET is an on-going phase III study comparing pralsetinib to a platinum-based chemotherapy in treatment naïve patients with RET fusion-positive metastatic NSCLC (NCT04222972) [135]. Similarly, LIBRETTO-431 is another phase III study comparing selpercatinib to platinum-based and pemetrexed chemotherapy with or without pembrolizumab in the first-line treatment of advanced RET fusion-positive NSCLC (NCT04194944) [136]. On-target RET G810 solvent front mutations detected in plasma and/or tissue samples, conferred resistance to selpercatinib in patients with KIF5B-RET and CCDC6-RET fusion-positive NSCLC [137]. NCT04161391 is an ongoing phase I/II study of TPX-0046, a RET/SRC inhibitor in advanced/metastatic solid tumours with RET fusions or mutations [138]. Off-target mechanisms of resistance include MET amplification and activation of other bypass pathways which could be targeted by combination strategies [139].

\section{NTRK}

NTRK gene fusions result in tropomyosin receptor kinase (TRK) fusion proteins that drive tumorigenesis in many solid tumours including lung, salivary gland, thyroid and sarcoma. NTRK fusions are found in $<1 \%$ of patients with NSCLC and do not overlap with other driver oncogenes [140-142]. They are independent of age, sex, smoking history and NSCLC histological subtype [141]. NRTK1-3 gene fusions encode oncogenic TRKA-C fusion proteins, respectively, that can be targeted by therapies in development, including larotrectinib (LOXO-101) and entrectinib (RXDX-101). Larotrectinib and entrectinib were both shown to have marked and durable efficacy in NSCLC with NTRK fusions [140, 143]. A pooled analysis of three phase I/II trials of larotrectinib in 159 adult and paediatric patients with advanced solid tumours including 12 patients with lung cancer (8\%) who had received prior therapy, resulted in an ORR of 79\% (16\% complete responses) and a good safety profile. In the overall population, the mDOR was 35.2 months and mPFS was 28.3 months [144]. Larotrectinib is the first tumour-agnostic drug to receive a European Medicines Agency (EMA) approval for the treatment of advanced solid tumours with NTRK gene fusion in adult and paediatric patients who have no satisfactory alternative therapeutic options. Similarly, in an integrated analysis of three phase I/II trials (ALKA-372-001, STARTRK-1 and STARTRK-2) of patients with metastatic or locally advanced solid tumours harbouring oncogenic NTRK1, 
NTRK2 and NTRK3 gene fusions, entrectinib achieved an ORR of 57\% (7\% complete responses), an mDOR of 10 months, mPFS of 11 months and a good tolerance profile. 10 of the 54 patients who were included in the study had advanced NSCLC; ORR in this subpopulation was 70\% [145]. In June 2020, the EMA granted a conditional marketing authorisation to entrectinib for the treatment of solid tumours expressing NTRK gene fusions. On-target resistance mechanisms to first-generation TRK inhibitors (larotrectinib and entrectinib) include solvent-front mutations (G595R, G639R, G623R), gatekeeper mutations (F589L, F633L, F627L) and xDFG mutations (G667C, G709C, G696A) [146]. These mutations could be sensitive to second-generation TRK inhibitors, such as repotrectinib (ongoing TRIDENT-1 trial, ORR 50\% in six TKI-pre-treated patients in the EXP-6 cohort) and selitrectinib [103, 147]. Off-target resistance mechanisms include KRAS mutation, MET amplification, BRAF mutation and IGF1R activation [146].

\section{HER2}

HER2/ERBB2 alterations in NSCLC can serve as primary or secondary oncogenic drivers after treatment with targeted therapies. They include mutations, amplifications and protein overexpression [148].

HER2 overexpression without mutation or amplification is able to induce de novo NSCLC in mouse models [149]. It is observed in 10-30\% of NSCLCs and is associated with papillary histology and poor disease prognosis [150-154]. High protein overexpression (IHC score 3) is often the consequence of HER2 amplification [148]. In a study by DE LANGEN et al. [155], HER2 protein overexpression increased after EGFR TKI treatment, thus resulting in a selected HER2-driven resistant cell population. The benefit from the use of trastuzumab in patients with HER2 overexpression or amplification is inconsistent; the monoclonal antibody might be more efficient in HER2-mutant tumours. Moreover, ado-trastuzumab emtansine, a HER2-specific antibody-drug conjugate, only showed a modest benefit (ORR 20\%) in patients with $\mathrm{IHC}^{+}$overexpression of HER2 (no responses in the $\mathrm{IHC}^{+}$cohort) [156].

HER2 amplification, classically detected using fluorescent in situ hybridisation, is present in 2-5\% of lung ADCs, particularly in females, never-smokers and patients with pleural effusions [154, 157, 158]. Adotrastuzumab emtansine achieved an ORR of 55\% in 11 patients with HER2-amplified NSCLC [159].

ERBB2 kinase domain mutations were reported in 1.5\% of NSCLC cases and had a higher prevalence in females and nonsmokers [152]. Genetically, they are less diverse than EGFR alterations, with 96\% consisting of exon 20 insertions [160]. HER2 mutations are associated with a poorer prognosis in lung ADC [161, 162]. With the implementation of NGS, HER2 mutations are routinely identified and are considered an oncogenic driver in NSCLC as well as a mechanism of acquired resistance after targeted therapy [148]. HER2 kinase domain mutations such as Y772_A775dup activates HER2 and EGFR, thus inducing resistance to EGFR TKI treatment [163]. Y772_A775dup occurred in one out of 60 patients treated with osimertinib in the AURA study [164]. HER2 protein expression is an insufficient surrogate marker for HER2 mutations [165]. The latter can be detected using liquid biopsies as demonstrated in a study by LEE et al. [166] and are not strictly associated with HER2 overexpression or amplification [165]. To date, there are no approved anti-HER2 targeted agents in HER2-mutant NSCLC [167]. Pan-HER TKIs such as dacomitinib, afatinib, neratinib, poziotinib and pyrotinib were evaluated in small-sized studies with variable response rates (between 3.8\% and 5.8\%) and PFS rates ranging from 3.7 to 6.4 months. The efficacy of these agents is moderate in comparison to EGFR, ALK or ROS1 TKIs [148]. Of these drugs, poziotinib seems to have the most promising results, especially in targeting HER2 exon 20 mutations [168]. Osimertinib is active in vitro against the relatively rare L775P and L775S mutations, but is less effective than afatinib or neratinib in patients with Y772_A775dup mutation [169]. The combination of trastuzumab with pertuzumab, a recombinant humanised monoclonal antibody that specifically targets the HER2 dimerisation domain, thus blocking ligand-dependent heterodimerisation of HER2 with other HER family members, has shown limited activity in the phase IIa MyPathway basket trial which included 30 patients with HER2-mutant or HER2-positive refractory NSCLC, with an ORR of $21 \%$ and $13 \%$, respectively [170]. Li et al. [171] treated 18 HER2-mutant advanced NSCLC patients with ado-trastuzumab emtansine as part of a phase 2 basket trial. Partial responses were achieved in $44 \%$ of the patients, mainly those with HER2 exon 20 insertions and point mutations in the kinase, transmembrane and extracellular domains. The median PFS was 5 months. HER2 protein expression measured using IHC or mass spectrometry was not predictive of response to treatment. Recently, trastuzumab deruxtecan (DS8201-a), a novel antibody-drug conjugate, achieved an ORR of 61.9\%, a mPFS of 14 months and an unreached mDOR in 42 patients with HER2-mutant NSCLC (cohort 2 of the DESTINY-Lung01 phase II trial) [172]. DESTINY-Lung01 also included 49 patients with HER2-overexpressing NSCLC (cohort 1). Results were promising albeit less spectacular in comparison with cohort 2 (ORR 24.5\%, mDOR 6 months 
TABLE 1 Approved targeted therapies in oncogene-driven nonsmall cell lung carcinoma

\begin{tabular}{|c|c|c|c|}
\hline & ASCO [173] & $\begin{array}{l}\text { ESMO }^{\#}[174]+\text { updated version } \\
\text { published } 15 \text { September } 2020\end{array}$ & $\begin{array}{c}\mathrm{NCCN}^{4}[167]+\text { updated version } \\
\text { April } 2021\end{array}$ \\
\hline $\begin{array}{l}\text { EGFR-sensitising } \\
\text { mutations }\end{array}$ & $\begin{array}{l}\text { Afatinib, erlotinib or gefitinib } \\
\text { Evidence quality: high } \\
\text { Strength of recommendation: strong } \\
\text { for each }\end{array}$ & $\begin{array}{l}\text { Erlotinib, gefitinib or afatinib (I, A), } \\
\text { or dacomitinib (I, B; MCBS score: } 3 \text { ) } \\
\text { None of the four EGFR TKIs is } \\
\text { consensually considered as a } \\
\text { preferred option (IV, C) } \\
\text { Osimertinib (I, A; MCBS score: 4) } \\
\text { Erlotinib and bevacizumab (II, B; } \\
\text { MCBS score: 3) } \\
\text { Erlotinib and ramucirumab (I, B; } \\
\text { MCBS score 3) } \\
\text { Gefitinib+carboplatin and } \\
\text { pemetrexed is a first-line option (I, B; } \\
\text { not EMA-approved) } \\
\text { Atezolizumab and bevacizumab with } \\
\text { carboplatin and paclitaxel may be } \\
\text { used after targeted therapies (III, A; } \\
\text { not EMA-approved) }\end{array}$ & $\begin{array}{c}\text { Afatinib (other recommended) } \\
\text { Erlotinib (other recommended) } \\
\text { Dacomitinib (other recommended) } \\
\text { Gefitinib (other recommended) } \\
\text { Osimertinib (preferred) } \\
\text { Erlotinib+ramucirumab } \\
\text { Erlotinib+bevacizumab (nonsquamous) }\end{array}$ \\
\hline EGFR T790M mutation & $\begin{array}{c}\text { Osimertinib } \\
\text { Evidence quality: high } \\
\text { Strength of recommendation: strong }\end{array}$ & Osimertinib (I, A; MCBS score: 4) & Osimertinib (category 1 ) \\
\hline$A L K$ fusions first-line & $\begin{array}{c}\text { Crizotinib } \\
\text { Evidence quality: strong } \\
\text { Strength of recommendation: high }\end{array}$ & $\begin{array}{c}\text { Crizotinib (I, A; MBCS score: 4), } \\
\text { ceritinib (I, B; MCBS score: 4), } \\
\text { alectinib (I, A; MCBS: 4), brigatinib } \\
\text { (I, B; not EMA-approved), ensartinib (I, } \\
\text { A; not EMA-approved) } \\
\text { CNS involvement: alectinib (III, A), } \\
\text { brigatinib (III, B) or ceritinib (IV, B) }\end{array}$ & $\begin{array}{c}\text { Alectinib (preferred) } \\
\text { Ceritinib (other recommended) } \\
\text { Brigatinib (other recommended) } \\
\text { Crizotinib (useful in certain } \\
\text { circumstances) } \\
\text { Lorlatinib }\end{array}$ \\
\hline $\begin{array}{l}\text { ALK fusions subsequent } \\
\text { therapy }\end{array}$ & & $\begin{array}{l}\text { Ceritinib and alectinib after } \\
\text { crizotinib (I, A; MBCS score: } 4 \text { ) } \\
\text { Brigatinib after crizotinib (III, A; } \\
\text { MCBS score: } 3 \text { ) } \\
\text { Lorlatinib in patients who progress } \\
\text { after a second-generation ALK TKI } \\
\text { (III, A; MCBS score: } 3 \text { ) }\end{array}$ & Alectinib, brigatinib, lorlatinib, ceritinib \\
\hline $\begin{array}{l}\text { ROS1 rearrangement } \\
\text { first-line }\end{array}$ & $\begin{array}{l}\text { Crizotinib (informal consensus) } \\
\quad \text { Evidence quality: low } \\
\text { Strength of recommendation: weak }\end{array}$ & $\begin{array}{l}\text { Crizotinib (III, A; MBCS score: 3) } \\
\text { Ceritinib (III, C; not EMA approved) }\end{array}$ & $\begin{array}{c}\text { Crizotinib (category 2A; preferred) } \\
\text { Entrectinib (category 2A; preferred) } \\
\text { Ceritinib (category 2A) }\end{array}$ \\
\hline $\begin{array}{l}\text { ROS1 rearrangement } \\
\text { subsequent lines }\end{array}$ & & $\begin{array}{l}\text { Lorlatinib (III, B), repotrectinib } \\
\text { (III, B), entrectinib (III, B; MCBS } \\
\text { score: } 3 \text { ) }\end{array}$ & $\begin{array}{c}\text { Lorlatinib (category } 2 \mathrm{~A} \text { ) } \\
\text { Entrectinib }\end{array}$ \\
\hline $\begin{array}{l}\text { BRAF V600E mutation } \\
\text { positive first-line and } \\
\text { subsequent therapy }\end{array}$ & $\begin{array}{l}\text { In patients who have received prior } \\
\text { immune checkpoint therapy, } \\
\text { dabrafenib alone or in combination } \\
\text { with trametinib in third-line is an } \\
\text { option (informal consensus) } \\
\text { Evidence quality: insufficient } \\
\text { Strength of recommendation: } \\
\text { moderate }\end{array}$ & $\begin{array}{l}\text { Dabrafenib and trametinib in first- or } \\
\text { second-line (III, A; MBCS score: } 2 \text { ) }\end{array}$ & Dabrafenib and trametinib (category $2 \mathrm{~A}$ ) \\
\hline $\begin{array}{l}\text { NTRK fusion } \\
\text { first-line/subsequent } \\
\text { therapy }\end{array}$ & & $\begin{array}{l}\text { Larotrectinib (III, A; MCBS score: 3), } \\
\text { entrectinib (III, B; MCBS score: 3) }\end{array}$ & $\begin{array}{l}\text { Entrectinib (category 2A) } \\
\text { Larotrectinib (category 2A) }\end{array}$ \\
\hline ERBB2 & & Trastuzumab deruxtecan (III, B) & \\
\hline $\begin{array}{l}\text { MET exon } 14 \text { skipping } \\
\text { mutation } \\
\text { first-line/subsequent } \\
\text { therapy }\end{array}$ & & $\begin{array}{c}\text { Crizotinib (III, B) } \\
\text { Capmatinib (III, B), tepotinib (III, B) }\end{array}$ & $\begin{array}{l}\text { Crizotinib } \\
\text { Capmatinib } \\
\text { Tepotinib }\end{array}$ \\
\hline
\end{tabular}


TABLE 1 Continued

\begin{tabular}{|c|c|c|}
\hline & $\begin{array}{l}\text { ESMO }^{\#}[174]+\text { updated version } \\
\text { published } 15 \text { September } 2020\end{array}$ & $\begin{array}{c}\mathrm{NCCN}^{4}[167]+\text { updated version } \\
\text { April } 2021\end{array}$ \\
\hline $\begin{array}{l}\text { RET rearrangement } \\
\text { positive first-line/ } \\
\text { subsequent }\end{array}$ & $\begin{array}{c}\text { Not currently routinely } \\
\text { recommended and recruitment into } \\
\text { open trials is encouraged (II, C) } \\
\text { Selpercatinib (III, B), pralsetinib } \\
\text { (III, B) }\end{array}$ & $\begin{array}{l}\text { Selpercatinib } \\
\text { Pralsetinib } \\
\text { Cabozantinib } \\
\text { Vandetanib }\end{array}$ \\
\hline \multicolumn{3}{|c|}{$\begin{array}{l}\text { ASCO: American Society of Clinical Oncology; ESMO: European Society for Medical Oncology; NCCN: National Comprehensive Cancer Network; EGFR: } \\
\text { epidermal growth factor receptor; ALK: anaplastic lymphoma kinase; ROS proto-oncogene 1; MCBS: magnitude of clinical benefit scale; TKI: tyrosine } \\
\text { kinase inhibitor; EMA: European Medicines Agency; CNS: central nervous system. ": ECMO-MCBS v1.1 for new therapy/indication approved by the } \\
\text { EMA since } 1 \text { January 2016. The score has been calculated by the ESMO-MCBS working group and validated by the ESMO guidelines committee. } \\
\text { Levels of evidence (I to V) and grades of recommendation (A to E) for the ESMO guidelines are adapted from the Infectious Diseases Society of } \\
\text { America-United States Public Health Service Grading System [175]; ": NCCN categories of evidence and consensus include category } 1 \text { (based upon } \\
\text { high-level evidence, there is uniform NCCN consensus that the intervention is appropriate), category } 2 \mathrm{~A} \text { (based upon lower-level evidence, there is } \\
\text { uniform NCCN consensus that the intervention is appropriate), category 2B (based upon lower-level evidence, there is NCCN consensus that the } \\
\text { intervention is appropriate) and category } 3 \text { (based upon any level of evidence, there is major NCCN disagreement that the intervention is } \\
\text { appropriate). }\end{array}$} \\
\hline
\end{tabular}

and mPFS 5.4 months). Trastuzumab deruxtecan was granted FDA breakthrough therapy designation for patients with advanced HER2-mutant NSCLC and disease progression on or after platinum-based therapy.

Table 1 lists the currently approved targeted therapies in oncogene-driven NSCLC.

\section{Liquid biopsy}

Molecular testing has become an inevitable standard in thoracic oncology. Oncologists are now confronted with another challenge on how to select tissue biopsy versus liquid biopsy to identify driver alterations and guide treatment decisions in NSCLC [176]. The term liquid biopsy refers to the analysis of plasma circulating tumour cells (CTC) or circulating tumour DNA (ctDNA). Other analytes in the peripheral blood include circulating cell-free DNA (cfDNA), circulating cell-free RNA (cfRNA), circulating extracellular vesicles and tumour educated platelets, as well as proteins and metabolites [177]. In addition, molecular analysis could be conducted on urine, pleural and sputum samples. While ctDNA might derive from apoptotic cells, the other analytes may be the product of viable cells, thus suggesting a possible difference in the acquired information. Hence, comparative studies between the different analytes are needed [177]. In addition, combination strategies of the different analytes that result in an optimal characterisation of a tumour are still lacking [177]. Compared to tissue biopsy, liquid biopsy is a simple, noninvasive method with an almost nonexistent complication rate, which is therefore much more appealing to patients, particularly those who are unfit or elderly. It is mostly useful and therefore recommended when tumour tissue is scarce or when there is bone-only metastatic disease, as the bone decalcification solutions can damage tumour DNA. It provides a global perspective since the collected tumour cells/DNA may be derived from several tumour sites and therefore partially resolves the problem of tumour heterogeneity. However, the accuracy in reflecting the heterogeneity of a tumour and its subclones or all tumour lesions in metastatic patients is yet to be determined [177]. Serial assessments can be performed with phylogenetic ctDNA construction, thus facilitating response monitoring and allowing for an earlier detection of secondary resistance mutations and eventually, earlier switching of targeted therapies. Moreover, liquid biopsy may be used to determine TMB, an important predictive biomarker for ICI response [176, 178, 179]. In addition, ctDNA variant allele frequency (VAF) and pre-treatment ctDNA concentration are a reflection of tumour burden and metabolic tumour volume, respectively [177]. Furthermore, liquid biopsy is being tested as a screening tool for early detection of cancer [180]. The major limitation of this technique remains in its lower sensitivity compared to tissue biopsy ( $\sim 85 \%$ in advanced-stage disease using the most sensitive assays) [179]. The isolated DNA is highly fragmented, has a short half-life and a low overall yield. The VAF is often low in the range of background noise of analytical methods. In addition, standard operating procedures are still lacking [177]. Tumour burden and anatomical site of disease have a clear impact on the sensitivity of liquid biopsies within and across cancer types [181]. Among the methods developed to improve the sequencing sensitivity are unique molecular identifiers, i.e. molecular barcodes that facilitate bioinformatic alignment of sequences derived from the same DNA fragment, thus increasing the accuracy (number of errors per base pair sequenced) [177]. Other solutions to increase sensitivity include enriching for ctDNA fragments on the basis of their length, since they are shorter than normal cfDNA [177]. The International Association for the Study of Lung Cancer (IASLC) guidelines provide a comprehensive review 
of the pros and cons of liquid biopsy in NSCLC [179]. Clinicians should have a thorough understanding of the test's characteristics and its validation against a reference standard such as tissue genotyping. They should recognise the differences between the available assays and be able to select the correct patients for liquid biopsy versus tissue biopsy and to correctly interpret the results of the assay [182].

\section{cfDNA/ctDNA}

Upon cell death or apoptosis, cfDNA, composed mostly of germline DNA, is released into the bloodstream. The concept of cfDNA "shed", meaning the release of tumour DNA into the circulation, is central to the development and interpretation of plasma genotyping assays. The concentration of cfDNA in the plasma is directly proportional to the rate of cfDNA shedding by the tumour and indirectly proportional to the rate of DNA elimination by renal clearance. It is also related to the overall burden of metastatic disease, the presence of particular metastatic sites such as the liver or the bone, the mitotic rate as well as the amount of tumour necrosis and vascularisation [183-185]. In contrast, the analysis of plasma cfDNA testing in patients with isolated brain metastases has limited sensitivity [186].

Droplet digital (dd)PCR and beads, emulsions, amplification and magnetics (BEAMing) PCR are highly sensitive and specific currently used molecular platforms that employ emulsion technology to quantify the amount of mutant DNA in the plasma of patients with advanced NSCLC $[185,187]$. The main limitation of these assays is their inability to detect complex genomic alterations and perform multiplex testing. They can be used to detect and monitor levels of common EGFR and KRAS mutations [187, 188]. NGS assesses larger panels and detects complex alterations including rearrangements, but is slower than ddPCR. Moreover, its sensitivity to detect copy number alterations remains low. Multiple NGS-based commercial plasma genotyping assays are available (Guardant360, FoundationACT). Both PCR and NGS are valid approaches for plasma genotyping. Rigorous validation of the available assays against a reference standard within a given tumour type, stage and treatment time point is crucial to ensure reliability of the obtained results [182].

Applications of liquid biopsy in NSCLC

Identification of driver alterations

The best-validated clinical context for use of plasma cfDNA is in newly diagnosed NSCLC to guide treatment selection, because tumour shedding is considerably reduced in patients already receiving treatment. Given the high specificity of validated plasma-based assays, the identification of an actionable driver alteration should be considered as sufficient evidence to start treatment with the corresponding targeted therapy without the need for additional tissue biopsy.

The cobas EGFR Mutation Test v2 (Roche Molecular Diagnostics) is an FDA-approved cfDNA-based test that detects activating EGFR mutations in NSCLC patients. These mutations are a strong predictive biomarker of the efficacy of EGFR TKIs in this setting [185]. Other methods such as ddPCR, BEAMing and NGS have a higher sensitivity and their use is expanding. According to the IASLC recommendations, the detection of a sensitising EGFR mutation using the cobas EGFR mutation test v2 or ddPCR on ctDNA is sufficient to start treatment with EGFR TKIs. A negative result mandates further evaluation with either a NGS-based test of ctDNA or tissue biopsy. Plasma genotyping may be particularly useful in situations where a tissue biopsy is not feasible or where there is an urgent need to rapidly identify a driver alteration [182]. Circulating tumour DNA studies were successful in detecting somatic mutations that had been missed in the corresponding tissue samples, thus highlighting the concept of intratumour heterogeneity and subclonal mutations [177]. Liquid biopsy may also be used to exclude the presence of other potential drivers, particularly when a KRAS mutation (non-overlapping with EGFR and $A L K$ alterations) is identified [182]. In addition, mutant allele fraction quantified by NGS, ddPCR or BEAMing should be carefully considered in the interpretation of plasma cfDNA results. In the AURA3 study of osimertinib versus platinum-pemetrexed for T790M mutation-positive advanced NSCLC, the plasma T790M positive percentage agreement was 51\% by cobas testing, $58 \%$ by ddPCR and $66 \%$ by NGS, suggesting that all three test platforms are suitable for routine clinical practice [189]. Caution is advised when interpreting mutations that are positive at low levels (allelic fraction $<1 \%$ using the latter quantitative assays) as they might represent false positives (assay artefacts). In a recent noninferiority prospective study of treatment-naïve patients with NSCLC, Guardant360, a validated cfDNA test identified guideline-recommended biomarkers at a rate at least as high as standard-of-care tissue genotyping with high tissue concordance and shorter median turnaround time [190]. Despite these promising results, negative cfDNA sequencing is not sufficient to rule out the presence of driver mutations and tissue genotyping remains the standard diagnostic procedure. B-FAST (NCT03178552) is an on-going phase II/III, global, multicentre, open-label, multi-cohort study designed to evaluate the safety and efficacy of targeted therapies or immunotherapy as single agents or in combination in patients 
with advanced NSCLC and driver mutations or high TMB as identified by two blood-based NGS ctDNA assays [191].

Compared to EGFR mutations, data on $A L K$ rearrangement assessment using ctDNA in treatment-naïve patients are less convincing with NGS reaching acceptable levels of sensitivity. The sensitivity of ddPCR is much higher than that of reverse transcriptase (RT)-PCR in detecting $A L K$ rearrangements; however, prospective studies are awaited [179]. The IASLC recommends against the use of PCR for ALK or ROS1 rearrangement detection from ctDNA [179].

Multiplex panels using NGS platforms on ctDNA detect fewer common mutations and have acceptable levels of sensitivity and optimal levels of specificity to initiate first-line therapy in patients with EGFR, $A L K, R O S 1$ and BRAF alterations. In addition, cfRNA can be used for the measurement of RNA transcripts of fusion genes (NTRK, ALK, ROS1, RET) and MET-14 splicing variant by RT-PCR [179]. Again, a negative plasma result mandates a tissue biopsy to formally exclude the presence of a driver alteration [179].

\section{Identification of resistance mechanisms}

Identifying resistance mechanisms and guiding subsequent therapy decisions is another useful application of liquid biopsy in NSCLC, particularly in EGFR-mutant disease where identification of a T790M mutation is an indication to switch from first-/second-generation EGFR TKIs to osimertinib therapy [185]. Furthermore, due to tumour heterogeneity, T790M mutation might not be identified in all tumour sites which, again, highlights the utility of plasma biopsy [182]. T790M mutation could also be detected in urine and pleural fluid samples [192, 193]. The concordance rate of T790M testing in plasma and tissue is up to $74 \%$ [194]. Moreover, the profile of resistance alterations after treatment with osimertinib is becoming clinically relevant with the advent of fourth-generation EGFR TKIs and with strategies that impair parallel pathway activation [195, 196]. The MELROSE phase II trial is an ongoing French multicentric study whose primary objective is to determine the genetic tumour profile at progression after first-line therapy with osimertinib in patients with EGFR-sensitising mutations, using both tissue biopsy and ctDNA [197]. In patients progressing after first-line EGFR TKIs, the IASLC recommends an NGS multiplex panel over PCR methods, as it could also detect fewer common alterations. Negative results need to be confirmed by NGS testing on tissue biopsies. Of note, liquid biopsy cannot detect small cell lung cancer transformation; the co-detection of TP53/RB1 loss (associated with a $\times 43$ higher risk of transformation to small cell lung cancer) on a liquid biopsy does not indicate that a transformation has occurred [198]. In this setting, tissue biopsies are critical upon disease progression.

The use of liquid biopsy, and particularly NGS-based techniques, is currently emerging as a means for detecting $A L K$ resistance alterations in patients progressing during $A L K$ TKIs. This approach has not yet been implemented in daily practice; however, the detection of certain mutations can help select the subsequent ALK TKI to treat patients. For instance, $I 1171 \mathrm{~T}$ and the $V 1180 \mathrm{~L}$ mutations confer resistance to alectinib and crizotinib but not to ceritinib; L1196M or S1206Y mutations confer resistance to crizotinib but not ceritinib; G1202R, G1123S or F1174 mutations confer resistance to crizotinib [199, 200]. PAILLER et al. [201] explored resistance mutations in CTCs isolated at the single-cell level from 17 patients with ALK-rearranged advanced NSCLC who progressed on crizotinib and lorlatinib. They identified an array of co-occurring mutations (mainly the RTK-KRAS and TP53 pathways) in ALK-independent pathways in nine out of 14 crizotinib-resistant patients. Additionally, in one lorlatinib-resistant patient, they found two compound ALK mutations G1202R/F1174C and G1202R/T1151M, a previously described "on-target" resistance mechanism.

The CHRONOS trial is currently testing the efficacy of a second anti-EGFR treatment in the third-line setting, in patients with RAS-wild metastatic colorectal carcinoma who received anti-EGFR agents in the first-line setting and who had a $>50 \%$ drop in ctDNA RAS levels ( $R A S$ mutation being the most common resistance mechanism to anti-EGFR therapy) [202]. This approach would be particularly interesting in thoracic oncology where the decay of resistance mutations over time following the withdrawal of targeted therapy might allow for an effective rechallenge with a previously active targeted therapy [181].

Ortiz-Cuaran et al. [203] analysed ctDNA before treatment with anti-BRAF agents, upon response and progression. BRAF V600E mutation was detected in ctDNA in $72.7 \%$ of samples at baseline and in $54.3 \%$ of samples at disease progression during treatment with BRAF inhibitors. Longitudinal monitoring of ctDNA reflected the observed overall clinical and radiological tumour response. At baseline, BRAF mutations were associated with liver and adrenal metastases. The presence of concomitant activating mutations of FGFR2 and CTNNB1 was associated with a shorter time on BRAF TKIs. While reactivation 
of the MAPK pathway remained the most frequent resistance mechanism, other alterations in the PI3 K pathway as well as in IDH1, FGFR2 and CTNNB1 were identified and should be explored in upcoming studies.

\section{Monitoring of treatment response}

Besides its established use in newly diagnosed advanced NSCLC and in identifying secondary resistance to TKIs, plasma cfDNA could also be used to monitor treatment response. In a retrospective analysis of plasma samples in patients treated within the FASTACT-2 study, patients with undetectable mutant cfDNA after two cycles of therapy had a significantly longer PFS time compared to those with residual disease (12 months versus 7.2 months, hazard ratio 0.32; $<<0.0001$ ) [204]. Conversely, the persistence of T790M mutation in ctDNA 6 weeks after starting treatment with osimertinib in the AURA trial predicted a shorter mPFS (5.5 versus 10.9 months) and a decreased ORR (35\% versus 70\%) [205]. APPLE is an ongoing randomised, open-label, multicentre, phase II trial in advanced, EGFR-mutant, EGFR TKI-naïve NSCLC to evaluate the best strategy for sequencing gefitinib and osimertinib treatment. A cfDNA T790M test is used as a predictive marker for making treatment decisions in one of the three study arms. Positive results would prospectively validate the role of liquid biopsies in assessing tumour progression compared with standard radiological guidelines [206]. In addition, data from the AURA and FLAURA studies show that 15-32\% of patients with NSCLC do not shed ctDNA into the circulation and have a better prognosis than those with detectable ctDNA, the latter usually reflecting a higher tumour burden [207].

In the previously mentioned VISION study of tepotinib in patients with MET exon 14 skipping mutations, a high concordance was found between the molecular cfDNA response and clinical response on the basis of Response Evaluation Criteria in Solid Tumours measurement [119].

\section{Lung cancer screening}

Through a tumour-specific phylogenetic approach, the TRACERx (Tracking Non-Small-Cell Lung Cancer Evolution Through Therapy) study revealed the presence of lymphovascular invasion, the non-ADC histology and a high Ki67 proliferation index as three independent predictors of ctDNA detection. ${ }^{18} \mathrm{~F}$-2-fluoro-2-deoxy-D-glucose avidity on positron emission tomography predicted ctDNA detection and tumour volume from computed tomography (CT) analyses correlated with mean clonal plasma VAF. It was predicted that a primary tumour burden of $10 \mathrm{~cm}^{3}$ would result in a mean clonal plasma VAF of $0.1 \%$ (95\% CI 0.06-0.18\%). The minimal size and volume of a lung nodule detected by low-dose CT screening exam are $4 \mathrm{~mm}$ and $0.034 \mathrm{~cm}^{3}$, respectively, which would equate to a plasma VAF of $1.8 \times 10^{-4} \%$ (95\% CI $\left.9.8 \times 10^{-6}-0.0033 \%\right)$. The latter value being the extreme of detection limits of current ctDNA assays, the sensitivity of ctDNA-directed early-NSCLC screening remains low [208].

NCT03774758 is an ongoing prospective observational study of ctDNA dynamics using the Guardant Health ct-DNA LUNAR assay in patients who undergo lung cancer screening the San Francisco VA Medical Center, UCSF Medical Center and the San Francisco General Hospital (San Fransisco, CA, USA) [209]. The methylation of the promoter region of septin 9 (SEPT9), a tumour suppressor gene, is commonly observed in colorectal cancer and can be detected using ctDNA. PowrózeK et al. [210] found a SEPT9 promoter methylation in $44.3 \%$ of lung cancer patients with different histological subtypes and disease stages. Similar to colorectal cancer, identification of SEPT9 promoter methylation using ctDNA might be a useful biomarker in early diagnosis of lung cancer [181, 210].

Liquid biopsy may also be used to identify other tissue- and cancer-specific epigenetic alterations such as DNA hydroxymethylation, inferred histone occupancy and DNA fragment length [181].

Micro-RNAs extracted from peripheral blood mononucleated cells have also been used to diagnose NSCLC with a sensitivity and specificity rates nearing $71.43 \%$ and $82.61 \%$, respectively [211]. Furthermore, a panel of four miRNAs extracted from exosomes could detect lung cancer with 96\% sensitivity and $60 \%$ specificity in a retrospective cohort of 30 people of whom 10 had lung cancer [212].

Combining ctDNA with low-dose CT of the chest could possibly improve the positive predictive value of the latter exam in lung cancer screening and reduce the need for unnecessary and potentially harmful follow-up procedures. In addition, improving the sensitivity of ctDNA testing to the point that it replaces imaging exams as a screening tool would reduce the risk of secondary radiation-induced cancers [181].

\section{Early detection of relapse in the adjuvant setting}

Liquid biopsy may serve as a future tool to identify earlier stage NSCLC patients at high risk of relapse, and to eventually personalise adjuvant therapy [182]. In the TRACERx study, patients with early NSCLC 
were followed-up regularly with serial liquid biopsies in addition to clinical and imaging assessment. Circulating tumour DNA detection in the plasma was defined as the detection of two out of 18 tumour-specific single-nucleotide variants (SNV) using multiplex-PCR assay panels. 13 (93\%) out of 14 relapsing patients had positive ctDNA before or at clinical relapse. The median lead time defined as the median interval between ctDNA detection and CT-confirmed NSCLC relapse was 70 days (range 10-346 days). Detection of SNVs in ctDNA after surgery predicted relapse and resistance to adjuvant chemotherapy [208].

\section{Liquid biopsy and immunotherapy}

The integration of liquid biopsies into immune-oncology is challenging, especially since tissue biopsy provides a more comprehensive overview of the tumour microenvironment. Copy number instability of cfDNA could be used as a predictive biomarker of response to immunotherapy [213]. PD-L1 expression, a prognostic and predictive biomarker of response to ICIs usually assessed on tissue samples, was detected in CTCs with a PD-L1 specific antibody and in extracellular vesicles by Western blotting [214, 215]. Assessment of TMB, another predictive biomarker of efficacy ICIs, was also performed on ctDNA samples using panels of 54-70 genes [216]. In a retrospective analysis of two large randomised trials, GANDARA et al. [217] showed that TMB measured in plasma (bTMB) was predictive of PFS (cut off $\geqslant 16$ derived from sequencing $1.1 \mathrm{Mb}$ of coding region) in patients treated with atezolizumab in second-line and higher NSCLC. In another cohort study of patients with NSCLC, a cancer gene panel named NCC-GP150 was used to estimate bTMB and correlated well with matched tumour TMB calculated by whole-exome sequencing. A bTMB $\geqslant 6$ was associated with a better PFS and ORR in patients treated with anti-PD1 or anti-PDL1 agents [218]. In a single-institution phase II study of pembrolizumab in patients with advanced solid tumours, changes in ctDNA levels from baseline to the third cycle of treatment were predictive of benefit to pembrolizumab across cancer types and clearance of ctDNA during treatment yielded superior clinical outcomes independent of tumour type, TMB or PD-L1 status [219]. Changes in variant allele frequencies of all mutations were correlated with tumour response to durvalumab in a phase I/II trial in 304 patients with advanced NSCLC [220]. Other studies are needed to establish the clinical validity of serial ctDNA assays before and during treatment with ICIs, as a prognostic, predictive and pharmacodynamic tool [219]. In addition, ctDNA liquid biopsy might aid in the selection of patients who can benefit from de-escalation of treatment (after clearance of detectable ctDNA) especially in the field of immune-oncology where the optimal duration of treatment with ICIs remains unclear.

\section{Conclusion}

Modern thoracic oncology and precision medicine are inseparable. With the recent genomic sequencing of NSCLC tumours, we now possess huge amounts of genomic data that will markedly improve our understanding of lung carcinogenesis in order to develop appropriate, less toxic and more effective treatment strategies. Liquid biopsy is a precious tool that facilitates tumour sampling and has thus become quite endearing to both patients and physicians. However, caution is advised due to the lower sensitivity of plasma-based assays that cannot thus far replace tissue genotyping. Ensuring clinical validity and clinical utility will allow liquid biopsies to reach their full potential and significantly impact precision oncology with subsequent optimisation of cancer care.

Provenance: Commissioned article, peer reviewed.

Previous articles in this series: No. 1: Eichhorn F, Winter H. How to handle oligometastatic disease in nonsmall cell lung cancer. Eur Respir Rev 30: 2021; 200234. No. 2: Asciak R, George V, Rahmna NM. Update on biology and management of mesothelioma. Eur Respir Rev 30: 2021; 200226. No. 3: Finazzi T, Schneiders FL, Senan S. Developments in radiation techniques for thoracic malignancies. Eur Respir Rev 30: 2021; 200224. No. 4: Huber RM, Kauffmann-Guerrero D, Hoffmann H, et al. New developments in locally advanced nonsmall cell lung cancer. Eur Respir Rev 30: 2021; 200227. No. 5: Rittmeyer A, Schiwitza A, Sahovic L, et al. Update on recent key publications in lung oncology: picking up speed. Eur Respir Rev 30: 2021; 200300.

Conflict of interest: P. Abdayem reports non-financial support from Pierre Fabre and Eli Lilly, outside the submitted work. D. Planchard reports personal fees, non-financial support and other from AstraZeneca, Pfizer and Roche; personal fees and other from Bristol-Myers Squibb, Boehringer Ingelheim, Daiichi Sankyo, Eli Lilly and Merck; personal fees from Celgene and Peer CME; personal fees and non-financial support from Prime Oncology; and other funding from Medimmun, Sanofi-Aventis, Taiho pharma and Novocure, outside the submitted work.

\section{References}

1 Hanahan D, Weinberg RA. Hallmarks of cancer: the next generation. Cell 2011; 144: 646-674.

2 Weinstein IB. Cancer. Addiction to oncogenes - the Achilles heal of cancer. Science 2002; 297 : 63-64. 
3

Chen Z, Fillmore CM, Hammerman PS, et al. Non-small-cell lung cancers: a heterogeneous set of diseases. Nat Rev Cancer 2014; 14: 535-546.

Ellison G, Zhu G, Moulis A, et al. EGFR mutation testing in lung cancer: a review of available methods and their use for analysis of tumour tissue and cytology samples. J Clin Pathol 2013; 66: 79-89.

Andre F, Delaloge S, Soria J-C. Biology-driven phase II trials: what is the optimal model for molecular selection? J Clin Oncol 2011; 29: 1236-1238.

Meador CB, Oxnard GR. Effective cancer genotyping - many means to one end. Clin Cancer Res 2019; 25 : 4583-4585.

Caso R, Sanchez-Vega F, Tan KS, et al. The underlying tumor genomics of predominant histologic subtypes in lung adenocarcinoma. J Thorac Oncol 2020; 15: 1844-1856.

Chen DS, Irving BA, Hodi FS. Molecular pathways: next-generation immunotherapy - inhibiting programmed death-ligand 1 and programmed death-1. Clin Cancer Res 2012; 18: 6580-6587.

Mitsudomi T, Steinberg SM, Oie HK, et al. ras gene mutations in non-small cell lung cancers are associated with shortened survival irrespective of treatment intent. Cancer Res 1991; 51: 4999-5002.

Slebos RJ, Hruban RH, Dalesio O, et al. Relationship between K-ras oncogene activation and smoking in adenocarcinoma of the human lung. J Natl Cancer Inst 1991; 83: 1024-1027.

Poulin EJ, Bera AK, Lu J, et al. Tissue-specific oncogenic activity of KRAS ${ }^{\mathrm{A1} 46 \mathrm{~T}}$. Cancer Discov 2019; 9: 738-755.

Friedlaender A, Drilon A, Weiss GJ, et al. KRAS as a druggable target in NSCLC: rising like a phoenix after decades of development failures. Cancer Treat Rev 2020; 85: 101978.

Singh A, Greninger P, Rhodes D, et al. A gene expression signature associated with "K-Ras addiction" reveals regulators of EMT and tumor cell survival. Cancer Cell 2009; 15: 489-500.

Kharbanda A, Rajabi H, Jin C, et al. MUC1-C confers EMT and KRAS independence in mutant KRAS lung cancer cells. Oncotarget 2014; 5: 8893-8905.

Skoulidis F, Byers LA, Diao L, et al. Co-occurring genomic alterations define major subsets of KRAS-mutant lung adenocarcinoma with distinct biology, immune profiles, and therapeutic vulnerabilities. Cancer Discov 2015; 5: 860-877.

Bange E, Marmarelis ME, Hwang W-T, et al. Impact of KRAS and TP53 co-mutations on outcomes after first-line systemic therapy among patients with STK11-mutated advanced non-small-cell lung cancer. JCO Precis Oncol 2019; 3: PO.18.00326.

Scheffler M, Ihle MA, Hein R, et al. K-ras mutation subtypes in NSCLC and associated co-occuring mutations in other oncogenic pathways. J Thorac Oncol 2019; 14: 606-616.

Renaud S, Guerrera F, Seitlinger J, et al. KRAS-specific amino acid substitutions are associated with different responses to chemotherapy in advanced non-small-cell lung cancer. Clin Lung Cancer 2018; 19: e919-e931.

Garassino MC, Marabese M, Rusconi P, et al. Different types of K-Ras mutations could affect drug sensitivity and tumour behaviour in non-small-cell lung cancer. Ann Oncol 2011; 22: 235-237.

Mazieres J, Drilon A, Lusque A, et al. Immune checkpoint inhibitors for patients with advanced lung cancer and oncogenic driver alterations: results from the IMMUNOTARGET registry. Ann Oncol 2019; 30: 1321-1328.

Dong Z-Y, Zhong W-Z, Zhang X-C, et al. Potential predictive value of TP53 and KRAS mutation status for response to PD-1 blockade immunotherapy in lung adenocarcinoma. Clin Cancer Res 2017; 23: 3012-3024.

Nagasaka M, Li Y, Sukari A, et al. KRAS G12C Game of Thrones, which direct KRAS inhibitor will claim the iron throne? Cancer Treat Rev 2020; 84: 101974.

Li B T, Skoulidis F, Falchook G, et al. PS01.07 Registrational Phase 2 Trial of Sotorasib in KRAS p.G12C Mutant NSCLC: First disclosure of the Codebreak 100 Primary analysis. J Thorac Oncol 2021; 16: 561.

Amgen. A Phase 3 Multicenter, Randomized, Open Label, Active-controlled, Study of AMG 510 Versus Docetaxel for the Treatment of Previously Treated Locally Advanced and Unresectable or Metastatic NSCLC Subjects With Mutated KRAS p.G12C. Report No.: NCT04303780. https://clinicaltrials.gov/ct2/show/ NCT04303780 Date last updated: April 2021. Date last accessed: 13 May 2021.

Janne PA, Rybkin II, Spira Al, et al. 2020. KRYSTAL-1: Activity and safety of Adagrasib (MRTX849) in Advanced/Metastatic Non-small-cell Lung Cancer Harboring KRAS G12C mutation. EORTC-NCI-AACR Symposium Abstract LBA3 presented 25 October 2020.

26 Janssen Research \& Development, LLC. A First-in-Human Study of the Safety, Pharmacokinetics, Pharmacodynamics, and Preliminary Antitumor Activity of JNJ-74699157 in Participants With Advanced Solid Tumors Harboring the KRAS G12C Mutation. www.clinicaltrials.gov/ct2/show/NCT04006301 Date last accessed: 13 August 2020. Date last updated: 6 November 2020.

Molina-Arcas M. Combination Therapies to Maximize the ES28.05 Impact of KRAS-G12C Inhibitors. J Thorac Oncol 2021; 16: s97.

Hata AN, Shaw AT. Resistance looms for KRAS ${ }^{G 12 C}$ inhibitors. Nat Med 2020; 26: 169-170.

Lynch TJ, Bell DW, Sordella R, et al. Activating mutations in the epidermal growth factor receptor underlying responsiveness of non-small-cell lung cancer to gefitinib. N Engl J Med 2004; 350: 2129-2139. 
Paez JG, Jänne PA, Lee JC, et al. EGFR mutations in lung cancer: correlation with clinical response to gefitinib therapy. Science 2004; 304: 1497-1500.

O'Kane GM, Bradbury PA, Feld R, et al. Uncommon EGFR mutations in advanced non-small cell lung cancer. Lung Cancer 2017; 109: 137-144.

Cortes-Funes H, Gomez C, Rosell R, et al. Epidermal growth factor receptor activating mutations in Spanish gefitinib-treated non-small-cell lung cancer patients. Ann Oncol 2005; 16: 1081-1086.

Tokumo M, Toyooka S, Kiura K, et al. The relationship between epidermal growth factor receptor mutations and clinicopathologic features in non-small cell lung cancers. Clin Cancer Res 2005; 11: 1167-1173.

Paik PK, Varghese AM, Sima CS, et al. Response to erlotinib in patients with EGFR mutant advanced non-small cell lung cancers with a squamous or squamous-like component. Mol Cancer Ther 2012; 11: 2535-2540.

Gainor JF, Varghese AM, Ou SH, et al. ALK rearrangements are mutually exclusive with mutations in EGFR or KRAS: an analysis of 1,683 patients with non-small cell lung cancer. Clin Cancer Res 2013; 19: 4273-4281.

Wu Y-L, Zhou C, Hu C-P, et al. Afatinib versus cisplatin plus gemcitabine for first-line treatment of Asian patients with advanced non-small-cell lung cancer harbouring EGFR mutations (LUX-Lung 6): an open-label, randomised phase 3 trial. Lancet Oncol 2014; 15: 213-222.

Sequist LV, Yang JC-H, Yamamoto N, et al. Phase III study of afatinib or cisplatin plus pemetrexed in patients with metastatic lung adenocarcinoma with EGFR mutations. J Clin Oncol 2013; 31: 3327-3334.

Mok TS, Wu Y-L, Thongprasert S, et al. Gefitinib or carboplatin-paclitaxel in pulmonary adenocarcinoma. N Engl J Med 2009; 361: 947-957.

Rosell R, Carcereny E, Gervais R, et al. Erlotinib versus standard chemotherapy as first-line treatment for European patients with advanced EGFR mutation-positive non-small-cell lung cancer (EURTAC) a multicentre, open-label, randomised phase 3 trial. Lancet Oncol 2012; 13: 239-246.

Wu Y-L, Zhou C, Liam C-K, et al. First-line erlotinib versus gemcitabine/cisplatin in patients with advanced EGFR mutation-positive non-small-cell lung cancer: analyses from the phase III, randomized, open-label, ENSURE study. Ann Oncol 2015; 26: 1883-1889.

Mok TSK, Cheng Y, Zhou X, et al. Updated overall survival (OS) from extended follow up in ARCHER 1050: a randomized phase III study comparing dacomitinib with gefitinib as first-line therapy for patients (pts) with EGFR mutations. Ann Oncol 2019; 30: ix200-ix201.

Ramalingam SS, Vansteenkiste J, Planchard D, et al. Overall survival with osimertinib in untreated, EGFR-mutated advanced NSCLC. N Engl J Med 2020; 382: 41-50.

Herbst RS, Tsuboi M, John T, et al. Osimertinib as adjuvant therapy in patients (pts) with stage IB-IIIA EGFR mutation positive (EGFRm) NSCLC after complete tumor resection: ADAURA. $J$ Clin Oncol 2020; 38: LBA5.

Saito $\mathrm{H}$, Fukuhara $\mathrm{T}$, Furuya $\mathrm{N}$, et al. Erlotinib plus bevacizumab versus erlotinib alone in patients with EGFR-positive advanced non-squamous non-small-cell lung cancer (NEJ026): interim analysis of an open-label, randomised, multicentre, phase 3 trial. Lancet Oncol 2019; 20: 625-635.

Nakagawa K, Garon EB, Seto T, et al. Ramucirumab plus erlotinib in patients with untreated, EGFR-mutated, advanced non-small-cell lung cancer (RELAY): a randomised, double-blind, placebo-controlled, phase 3 trial. Lancet Oncol 2019; 20: 1655-1669.

Maemondo M, Fukuhara T, Saito H, et al. NEJ026: Final overall survival analysis of bevacizumab plus erlotinib treatment for NSCLC patients harboring activating EGFR-mutations. J Clin Oncol 2020; 38: 9506.

Soo R, Han J-Y, Dimopoulou G, et al. VP3-2021: a randomized phase II study of second-line osimertinib (Osi) and bevacizumab (Bev) versus Osi in advanced non-small-cell lung cancer (NSCLC) with epidermal growth factor receptor (EGFR) and T790M mutations (mt): results from the ETOP BOOSTER trial. Ann Oncol. 2021; 32: $942-944$.

Noronha V, Patil VM, Joshi A, et al. Gefitinib versus gefitinib plus pemetrexed and carboplatin chemotherapy in EGFR-mutated lung cancer. J Clin Oncol 2020; 38: 124-136.

AstraZeneca. 2021. A phase III, open-label, randomized study of osimertinib with or without platinum plus pemetrexed chemo, as first-line treatment in patients with epidermal growth factor receptor (EGFR) mutation positive, locally advanced or metastatic non-small cell lung cancer (FLAURA2). Report No.: NCT04035486. https://clinicaltrials.gov/ct2/show/NCT04035486 Date last updated: May 2021. Date last accessed: 13 May 2021.

Gainor JF, Shaw AT. Emerging paradigms in the development of resistance to tyrosine kinase inhibitors in lung cancer. J Clin Oncol 2013; 31: 3987-3996.

Yu HA, Arcila ME, Rekhtman N, et al. Analysis of tumor specimens at the time of acquired resistance to EGFR-TKI therapy in 155 patients with EGFR-mutant lung cancers. Clin Cancer Res 2013; 19: 2240-2247.

Mok TS, Wu Y-L, Ahn M-J, et al. Osimertinib or platinum-pemetrexed in EGFR T790M-positive lung cancer. N Engl J Med 2017; 376: 629-640.

Oxnard GR, Miller VA, Robson ME, et al. Screening for germline EGFR T790M mutations through lung cancer genotyping. J Thorac Oncol 2012; 7: 1049-1052.

Wu S-G, Shih J-Y. Management of acquired resistance to EGFR TKI-targeted therapy in advanced non-small cell lung cancer. Mol Cancer 2018; 171: 38. 
Marcoux N, Gettinger SN, O'Kane G, et al. EGFR-mutant adenocarcinomas that transform to small-cell lung cancer and other neuroendocrine carcinomas: clinical outcomes. J Clin Oncol 2019; 37: 278-285.

Engelman JA, Zejnullahu K, Mitsudomi T, et al. MET amplification leads to gefitinib resistance in lung cancer by activating ERBB3 signaling. Science 2007; 316: 1039-1043.

Yonesaka K, Zejnullahu K, Okamoto I, et al. Activation of ERBB2 signaling causes resistance to the EGFR-directed therapeutic antibody cetuximab. Sci Transl Med 2011; 3: 99 ra86.

Lin L, Bivona TG. Mechanisms of resistance to epidermal growth factor receptor inhibitors and novel therapeutic strategies to overcome resistance in NSCLC patients. Chemother Res Pract 2012; 2012: 817297.

Su W, Zhang X, Cai X, et al. BIM deletion polymorphism predicts poor response to EGFR-TKIs in nonsmall cell lung cancer: an updated meta-analysis. Medicine 2019; 98: e14568.

Tanimoto A, Takeuchi S, Arai S, et al. Histone deacetylase 3 inhibition overcomes BIM deletion polymorphism-mediated osimertinib resistance in EGFR-mutant lung cancer. Clin Cancer Res 2017; 23: 3139-3149.

Suda K, Mizuuchi H, Maehara Y, et al. Acquired resistance mechanisms to tyrosine kinase inhibitors in lung cancer with activating epidermal growth factor receptor mutation - diversity, ductility, and destiny. Cancer Metastasis Rev 2012; 31: 807-814.

Bivona TG, Hieronymus $\mathrm{H}$, Parker J, et al. FAS and NF-kB signalling modulate dependence of lung cancers on mutant EGFR. Nature 2011; 471: 523-526.

Ramalingam SS, Cheng Y, Zhou C, et al. Mechanisms of acquired resistance to first-line osimertinib: preliminary data from the phase III FLAURA study. Ann Oncol 2018; 29: Suppl. 8, viii740.

Schoenfeld AJ, Chan JM, Kubota D, et al. Tumor analyses reveal squamous transformation and off-target alterations as early resistance mechanisms to first-line osimertinib in EGFR-mutant lung cancer. Clin Cancer Res 2020; 26: 2654-2663.

Park K, John T, Kim S-W, et al. Amivantanab (JNJ-61186372), an anti-EGFR-MET bispecific antibody, in patients with EGFR exon 20 insertion (exon20ins)-mutated non-small cell lung cancer (NSCLC). J Clin Oncol 2020; 38: 9512

Cho BC, Lee KH, Cho EK, et al. 12580 Amivantamab (JNJ-61186372), an EGFR-MET bispecific antibody, in combination with lazertinib, a 3rd-generation tyrosine kinase inhibitor (TKI), in advanced EGFR NSCLC. Ann Oncol 2020; 31: S813.

Sequist LV, Han JY, Ahn MJ, et al. Osimertinib plus savolitinib in patients with EGFR mutation-positive, METamplified, non-small-cell lung cancer after progression on EGFR tyrosine kinase inhibitors: interim results from a multicentre, open-label, phase 1 b study. Lancet Oncol 2020; 21: 373-386.

Yu HA, Baik CS, Gold K, et al. LBA62 Efficacy and safety of patritumab deruxtecan (U3-1402), a novel HER3 directed antibody drug conjugate, in patients (pts) with EGFR-mutated (EGFRm) NSCLC. Ann Oncol 2020; 31: 1189-1190.

Kwak EL, Bang Y-J, Camidge DR, et al. Anaplastic lymphoma kinase inhibition in non-small-cell lung cancer. N Engl J Med 2010; 363: 1693-1703.

Shaw AT, Yeap BY, Mino-Kenudson M, et al. Clinical features and outcome of patients with non-small-cell lung cancer who harbor EML4-ALK. J Clin Oncol 2009; 27: 4247-4253.

Soda M, Choi YL, Enomoto M, et al. Identification of the transforming EML4-ALK fusion gene in non-small-cell lung cancer. Nature 2007; 448: 561-566.

Solomon BJ, Mok T, Kim D-W, et al. First-line crizotinib versus chemotherapy in ALK-positive lung cancer. N Engl J Med 2014; 371: 2167-2177.

Solomon BJ, Kim D-W, Wu Y-L, et al. Final overall survival analysis from a study comparing first-line crizotinib versus chemotherapy in ALK-mutation-positive non-small-cell lung cancer. J Clin Oncol 2018; 36 : 2251-2258

Peters S, Camidge DR, Shaw AT, et al. Alectinib versus crizotinib in untreated ALK-positive non-small-cell lung cancer. N Engl J Med 2017; 377: 829-838.

Soria J-C, Tan DSW, Chiari R, et al. First-line ceritinib versus platinum-based chemotherapy in advanced ALK-rearranged non-small-cell lung cancer (ASCEND-4): a randomised, open-label, phase 3 study. Lancet 2017; 389: 917-929.

Peters S, Mok TSK, Gadgeel SM, et al. Updated overall survival (OS) and safety data from the randomized, phase III ALEX study of alectinib (ALC) versus crizotinib (CRZ) in untreated advanced ALK+ NSCLC. J Clin Oncol 2020; 38: 9518.

7 Zhou C, Kim S-W, Reungwetwattana T, et al. Alectinib versus crizotinib in untreated Asian patients with anaplastic lymphoma kinase-positive non-small-cell lung cancer (ALESIA): a randomised phase 3 study. Lancet Respir Med 2019; 7: 437-446.

Camidge R, Kim HR, Ahn M-J, et al. Brigatinib vs crizotinib in patients with ALK inhibitor-naive advanced ALK+ NSCLC: updated results from the phase III ALTA-1 L trial. Ann Oncol 2019; 30: ix183-ix202.

Horn L, Wang Z, Poddubskaya E, et al. Phase 3 Randomized Study of Ensartinib vs Crizotinib in Anaplastic Lymphoma Kinase (ALK)-Positive NSCLC Patients: eXalt3. IASLC 2020 Presidential Symposium, 8 August 2020. https://vps2020.iaslc.org/images/handouts/06_Leora_Horn.pdf 
Shaw AT, Bauer TM, de Marinis F, et al. First-line lorlatinib or crizotinib in advanced ALK-positive lung cancer. N Engl J Med 2020; 383: 2018-2029.

Azam M, Seeliger MA, Gray NS, et al. Activation of tyrosine kinases by mutation of the gatekeeper threonine. Nat Struct Mol Biol 2008; 15: 1109-1118.

Friboulet L, Li N, Katayama R, et al. The ALK inhibitor ceritinib overcomes crizotinib resistance in non-small cell lung cancer. Cancer Discov 2014; 4: 662-673.

Katayama R, Lovly CM, Shaw AT. Therapeutic targeting of anaplastic lymphoma kinase in lung cancer: a paradigm for precision cancer medicine. Clin Cancer Res 2015; 21: 2227-2235.

Solomon BJ, Besse B, Bauer TM, et al. Lorlatinib in patients with ALK-positive non-small-cell lung cancer: results from a global phase 2 study. Lancet Oncol 2018; 19: 1654-1667.

Besse B, Solomon BJ, Felip E, et al. Lorlatinib in patients (Pts) with previously treated ALK+ advanced non-small cell lung cancer (NSCLC): updated efficacy and safety. J Clin Oncol 2018; 36: 9032.

Cui JJ, Rogers E, Zhai D, et al. TPX-0131: A next generation macrocyclic ALK inhibitor that overcomes ALK resistant mutations refractory to current approved ALK inhibitors. Cancer Res 2020; 80: A5226.

Katayama R, Shaw AT, Khan TM, et al. Mechanisms of acquired crizotinib resistance in ALK-rearranged lung cancers. Sci Transl Med 2012; 4: 120ra17.

Cha YJ, Cho BC, Kim HR, et al. A case of ALK-rearranged adenocarcinoma with small cell carcinoma-like transformation and resistance to crizotinib. J Thorac Oncol 2016; 11: e55-e58.

Caumont C, Veillon R, Gros A, et al. Neuroendocrine phenotype as an acquired resistance mechanism in ALK-rearranged lung adenocarcinoma. Lung Cancer 2016; 92: 15-18.

Lin JJ, Shaw AT. Recent advances in targeting ROS1 in lung cancer. J Thorac Oncol 2017; 12: 1611-1625.

Davies KD, Doebele RC. Molecular pathways: ROS1 fusion proteins in cancer. Clin Cancer Res 2013; 19: 4040-4045.

Dugay F, Llamas-Gutierrez F, Gournay M, et al. Clinicopathological characteristics of ROS1- and $R E T$-rearranged NSCLC in caucasian patients: data from a cohort of 713 non-squamous NSCLC lacking KRAS/EGFR/HER2/BRAF/PIK3CA/ALK alterations. Oncotarget 2017; 8: 53336-53351.

Bergethon K, Shaw AT, Ou S-HI, et al. ROS1 rearrangements define a unique molecular class of lung cancers. J Clin Oncol 2012; 30: 863-870.

Gainor JF, Tseng D, Yoda S, et al. Patterns of metastatic spread and mechanisms of resistance to crizotinib in ROS1-positive non-small-cell lung cancer. JCO Precis Oncol 2017; 2017: PO.17.00063.

Shaw AT, Ou S-HI, Bang Y-J, et al. Crizotinib in ROS1-rearranged non-small-cell lung cancer. N Engl J Med 2014; 371: 1963-1971.

Shaw AT, Riely GJ, Bang Y-J, et al. Crizotinib in ROS1-rearranged advanced non-small-cell lung cancer (NSCLC): updated results, including overall survival, from PROFILE 1001. Ann Oncol 2019; 30: 1121-1126.

Lim SM, Kim HR, Lee J-S, et al. Open-label, multicenter, phase II study of ceritinib in patients with non-small-cell lung cancer harboring ROS1 rearrangement. J Clin Oncol 2017; 35: 2613-2618.

Song A, Kim TM, Kim D-W, et al. Molecular changes associated with acquired resistance to crizotinib in ROS1-rearranged non-small cell lung cancer. Clin Cancer Res 2015; 21: 2379-2387.

Sehgal K, Patell R, Rangachari D, et al. Targeting ROS1 rearrangements in non-small cell lung cancer with crizotinib and other kinase inhibitors. Transl Cancer Res 2018; 7: Suppl. 7, S779-S786.

Shaw AT, Solomon BJ, Chiari R, et al. Lorlatinib in advanced ROS1-positive non-small-cell lung cancer: a multicentre, open-label, single-arm, phase 1-2 trial. Lancet Oncol 2019; 20: 1691-1701.

Drilon A, Siena S, Dziadziuszko R, et al. Entrectinib in ROS1 fusion-positive non-small-cell lung cancer: integrated analysis of three phase 1-2 trials. Lancet Oncol 2020; 21: 261-270.

Cho BC, Drilon AE, Doebele RC, et al. Safety and preliminary clinical activity of repotrectinib in patients with advanced ROS1 fusion-positive non-small cell lung cancer (TRIDENT-1 study). J Clin Oncol 2019; $37: 9011$.

Cho BC, Doebele RC, Lin JJ, et al. 2020. Phase 1/2 TRIDENT-1 study of repotrectinib in patients with ROS1+ or NTRK advanced solid tumors. 2020 World Conference on Lung Cancer. January 2021. MA1107.

Turning Point Therapeutics. 2021. A Phase 1/2, Open-Label, Multi-Center, First-in-Human Study of the Safety, Tolerability, Pharmacokinetics, and Anti-Tumor Activity of TPX-0005 in Patients With Advanced Solid Tumors Harboring ALK, ROS1, or NTRK1-3 Rearrangements (TRIDENT-1). Report No.: NCT03093116. https:// clinicaltrials.gov/ct2/show/NCT03093116 Date last accessed: 13 May 2021. Date last updated: January 2021. Ou S-HI, Fujiwara Y, Shaw AT, et al. Efficacy of taletrectinib (AB-106/DS-6051b) in ROS1+ NSCLC: an updated pooled analysis of U.S. and Japan phase 1 studies. JTO Clin Res Rep 2021; 2: 100108.

Davies H, Bignell GR, Cox C, et al. Mutations of the BRAF gene in human cancer. Nature 2002; 417: 949-954.

Paik PK, Arcila ME, Fara M, et al. Clinical characteristics of patients with lung adenocarcinomas harboring BRAF mutations. J Clin Oncol 2011; 29: 2046-2051.

Planchard D, Besse B, Groen HJM, et al. Dabrafenib plus trametinib in patients with previously treated BRAF (V600E)-mutant metastatic non-small cell lung cancer: an open-label, multicentre phase 2 trial. Lancet Oncol 2016; 17: 984-993. 
Gautschi O, Milia J, Cabarrou B, et al. Targeted therapy for patients with BRAF-mutant lung cancer: results from the European EURAF cohort. J Thorac Oncol 2015; 10: 1451-1457.

Marchetti A, Felicioni L, Malatesta S, et al. Clinical features and outcome of patients with non-small-cell lung cancer harboring BRAF mutations. J Clin Oncol 2011; 29: 3574-3579.

mutations. N Engl J Med 2015; 373: 726-736.

Chan XY, Singh A, Osman N, et al. Role played by signalling pathways in overcoming BRAF inhibitor resistance in melanoma. Int J Mol Sci 2017; 18: 1527.

in the wall. Cancer Treat Rev 2018; 66: 82-94.

Planchard D, Smit EF, Groen HJM, et al. Dabrafenib plus trametinib in patients with previously untreated $\mathrm{BRAF}^{\mathrm{V} 600 \mathrm{E}}$-mutant metastatic non-small-cell lung cancer: an open-label, phase 2 trial. Lancet Oncol 2017; 18: 1307-1316.

Awad MM, Oxnard GR, Jackman DM, et al. MET exon 14 mutations in non-small-cell lung cancer are associated with advanced age and stage-dependent MET genomic amplification and c-Met overexpression. J Clin Oncol 2016; 34: 721-730.

Vansteenkiste JF, Van De Kerkhove C, Wauters E, et al. Capmatinib for the treatment of non-small cell lung cancer. Expert Rev Anticancer Ther 2019; 19: 659-671.

Frampton GM, Ali SM, Rosenzweig M, et al. Activation of MET via diverse exon 14 splicing alterations occurs in multiple tumor types and confers clinical sensitivity to MET inhibitors. Cancer Discov 2015; 5: 850-859. harboring MET mutations causing exon 14 skipping. Cancer Discov 2015; 5: 842-849.

Paik PK, Felip E, Veillon R, et al. Tepotinib in non-small-cell lung cancer with MET exon 14 skipping mutations. N Engl J Med 2020; 383: 931-943.

Zheng D, Wang R, Ye T, et al. MET exon 14 skipping defines a unique molecular class of non-small cell lung cancer. Oncotarget 2016; 7: 41691-41702.

J Thorac Oncol 2017; 12: 15-26.

Wu Y-L, Soo RA, Locatelli G, et al. Does c-Met remain a rational target for therapy in patients with EGFR TKI-resistant non-small cell lung cancer? Cancer Treat Rev 2017; 61: 70-81.

Wolf J, Seto T, Han J-Y, et al. Capmatinib (INC280) in METAex14-mutated advanced non-small cell lung cancer (NSCLC): efficacy data from the phase II GEOMETRY mono-1 study. J Clin Oncol 2019; 37: 9004.

Wolf J, Seto T, Han J-Y, et al. Capmatinib in MET exon 14-mutated or MET-amplified non-small-cell lung cancer. N Engl J Med 2020; 383: 944-957.

Recondo G, Bahcall M, Spurr LF, et al. Molecular mechanisms of acquired resistance to MET tyrosine kinase inhibitors in patients with MET exon 14-Mutant NSCLC. Clin Cancer Res 2020; 26: 2615-2625.

Engstrom LD, Aranda R, Lee M, et al. Glesatinib exhibits antitumor activity in lung cancer models and patients harboring MET exon 14 mutations and overcomes mutation-mediated resistance to type I MET inhibitors in nonclinical models. Clin Cancer Res 2017; 23: 6661-6672.

Ferrara R, Auger N, Auclin E, et al. Clinical and translational implications of RET rearrangements in non-small cell lung cancer. J Thorac Oncol 2018; 13: 27-45.

Gautschi O, Milia J, Filleron T, et al. Targeting RET in patients with RET-rearranged lung cancers: results from the global, multicenter RET registry. J Clin Oncol 2017; 35: 1403-1410.

European patients. J Thorac Oncol 2016; 11: 122-127.

Lee $\mathrm{SE}$, Lee $\mathrm{B}$, Hong $\mathrm{M}$, et al. Comprehensive analysis of RET and ROS1 rearrangement in lung adenocarcinoma. Mod Pathol 2015; 28: 468-479.

1 Lee S-H, Lee J-K, Ahn M-J, et al. Vandetanib in pretreated patients with advanced non-small cell lung cancer-harboring RET rearrangement: a phase II clinical trial. Ann Oncol 2017; 28: 292-297.

Drilon A, Rekhtman N, Arcila M, et al. Cabozantinib in patients with advanced RET-rearranged non-small-cell lung cancer: an open-label, single-centre, phase 2, single-arm trial. Lancet Oncol 2016; 17: 1653-1660.

Drilon A, Oxnard G, Wirth L, et al. PL02.08 Registrational results of LIBRETTO-001: a phase 1/2 trial of LOXO-292 in patients with RET fusion-positive lung cancers. J Thorac Oncol 2019; 14: S6-S7.

Gainor JF, Curigliano G, Kim D-W, et al. Registrational dataset from the phase I/II ARROW trial of pralsetinib (BLU-667) in patients (pts) with advanced RET fusion+ non-small cell lung cancer (NSCLC). J Clin Oncol 2020; 38: 9515.

Blueprint Medicines Corporation. A Randomized, Open-Label, Phase 3 Study of Pralsetinib Versus Standard of Care for First Line Treatment of RET Fusion-Positive, Metastatic Non-Small Cell Lung Cancer. www.clinicaltrials. gov/ct2/show/NCT04222972 Date last accessed: 6 August 2020. Date last updated: 30 October 2020. 
Eli Lilly and Company. A Study of Selpercatinib (LY3527723) in Participants With Advanced or Metastatic RET Fusion-Positive Non-Small Cell Lung Cancer (LIBRETTO-431). www.clinicaltrials.gov/ct2/show/NCT04194944 Date last accessed: 8 August 2020. Date last updated: 21 February 2021.

137 Solomon BJ, Tan L, Lin JJ, et al. RET solvent front mutations mediate acquired resistance to selective RET inhibition in RET-driven malignancies. J Thorac Oncol 2020; 15: 541-549.

138 Turning Point Therapeutics. A Phase 1/2 Study of TPX-0046, A Novel Oral RET/SRC Inhibitor in Adult Subjects with Advanced/Metastatic Solid Tumors Harboring Oncogenic RET Fusions or Mutations. Report No.: NCT04161391. Available from: https://clinicaltrials.gov/ct2/show/NCT04161391/ Date last accessed: 13 May 2021. Date last updated: April 2021.

139 Lin JJ, Liu SV, McCoach CE, et al. Mechanisms of resistance to selective RET tyrosine kinase inhibitors in RET fusion-positive non-small-cell lung cancer. Ann Oncol 2020; 31: 1725-1733.

140 Drilon A, Laetsch TW, Kummar S, et al. Efficacy of larotrectinib in TRK fusion-positive cancers in adults and children. N Engl J Med 2018; 378: 731-739.

141 Farago AF, Taylor MS, Doebele RC, et al. Clinicopathologic features of non-small-cell lung cancer harboring an NTRK gene fusion. JCO Precis Oncol 2018; 2018: PO.18.00037.

142 Gatalica Z, Xiu J, Swensen J, et al. Molecular characterization of cancers with NTRK gene fusions. Mod Pathol 2019; 32: 147-153.

143 Drilon A, Siena S, Ou S-HI, et al. Safety and antitumor activity of the multitargeted pan-TRK, ROS1, and ALK inhibitor entrectinib: combined results from two phase I trials (ALKA-372-001 and STARTRK-1). Cancer Discov 2017; 7: 400-409.

144 Hong DS, DuBois SG, Kummar S, et al. Larotrectinib in patients with TRK fusion-positive solid tumours: a pooled analysis of three phase $1 / 2$ clinical trials. Lancet Oncol 2020; 21: 531-540.

145 Doebele RC, Drilon A, Paz-Ares L, et al. Entrectinib in patients with advanced or metastatic NTRK fusion-positive solid tumours: integrated analysis of three phase 1-2 trials. Lancet Oncol 2020; 21: 271-282.

146 Drilon A. TRK inhibitors in TRK fusion-positive cancers. Ann Oncol 2019; 30: viii23-viii30.

147 Bayer. A Phase 1/2 Study of the TRK Inhibitor Selitrectinib in Adult and Pediatric Subjects with Previously Treated NTRK Fusion Cancers. Report No.: NCT03215511. https://clinicaltrials.gov/ct2/show/NCT03215511/ Date last accessed: 13 May 2021. Date last updated: April 2021.

148 Jebbink M, de Langen AJ, Boelens MC, et al. The force of HER2 - a druggable target in NSCLC? Cancer Treat Rev 2020; 86: 101996.

149 Liu S, Li S, Hai J, et al. Targeting HER2 aberrations in non-small cell lung cancer with osimertinib. Clin Cancer Res 2018; 24: 2594-2604.

150 Heinmöller P, Gross C, Beyser K, et al. HER2 status in non-small cell lung cancer: results from patient screening for enrollment to a phase II study of herceptin. Clin Cancer Res 2003; 9: 5238-5243.

151 Mazières $J$, Peters $S$, Lepage $B$, et al. Lung cancer that harbors an HER2 mutation: epidemiologic characteristics and therapeutic perspectives. J Clin Oncol 2013; 31: 1997-2003.

152 Shigematsu H, Takahashi T, Nomura M, et al. Somatic mutations of the HER2 kinase domain in lung adenocarcinomas. Cancer Res 2005; 65: 1642-1646.

153 Nakamura H, Kawasaki N, Taguchi M, et al. Association of HER-2 overexpression with prognosis in nonsmall cell lung carcinoma: a metaanalysis. Cancer 2005; 103: 1865-1873.

$154 \mathrm{Kim}$ EK, Kim KA, Lee CY, et al. The frequency and clinical impact of HER2 alterations in lung adenocarcinoma. PLoS One 2017; 12: e0171280.

155 de Langen AJ, Jebbink M, Hashemi SMS, et al. Trastuzumab and paclitaxel in patients with EGFR mutated NSCLC that express HER2 after progression on EGFR TKI treatment. Br J Cancer 2018; 119: 558-564.

156 Peters S, Stahel R, Bubendorf L, et al. Trastuzumab emtansine (T-DM1) in patients with previously treated HER2-overexpressing metastatic non-small cell lung cancer: efficacy, safety, and biomarkers. Clin Cancer Res 2019; 25: 64-72.

157 Landi L, Cappuzzo F. HER2 and lung cancer. Expert Rev Anticancer Ther 2013; 13: 1219-1228.

158 Hirsch FR, Varella-Garcia M, Franklin WA, et al. Evaluation of HER-2/neu gene amplification and protein expression in non-small cell lung carcinomas. Br J Cancer 2002; 86: 1449-1456.

159 Li BT, Michelini F, Misale S, et al. HER2-mediated internalization of cytotoxic agents in ERBB2 amplified or mutant lung cancers. Cancer Discov 2020; 10: 674-687.

160 Arcila ME, Chaft JE, Nafa K, et al. Prevalence, clinicopathologic associations, and molecular spectrum of ERBB2 (HER2) tyrosine kinase mutations in lung adenocarcinomas. Clin Cancer Res 2012; 18: 4910-4918.

161 Liu L, Shao X, Gao W, et al. The role of human epidermal growth factor receptor 2 as a prognostic factor in lung cancer: a meta-analysis of published data. J Thorac Oncol 2010; 5: 1922-1932.

162 Pillai RN, Behera M, Berry LD, et al. HER2 mutations in lung adenocarcinomas: a report from the Lung Cancer Mutation Consortium. Cancer 2017; 123: 4099-4105.

163 Wang SE, Narasanna A, Perez-Torres M, et al. HER2 kinase domain mutation results in constitutive phosphorylation and activation of HER2 and EGFR and resistance to EGFR tyrosine kinase inhibitors. Cancer Cell 2006; 10: 25-38. 
Ramalingam SS, Yang JC-H, Lee CK, et al. Osimertinib as first-line treatment of EGFR mutation-positive advanced non-small-cell lung cancer. J Clin Oncol 2018; 36: 841-849.

Li BT, Ross DS, Aisner DL, et al. HER2 amplification and HER2 mutation are distinct molecular targets in lung cancers. J Thorac Oncol 2016; 11: 414-419.

Lee J, Franovic A, Shiotsu Y, et al. Detection of ERBB2 (HER2) gene amplification events in cell-free DNA and response to anti-HER2 agents in a large Asian cancer patient cohort. Front Oncol 2019; 9: 212.

Ettinger DS, Aisner DL, Wood DE, et al. NCCN guidelines insights: non-small cell lung cancer, version 5.2018. J Natl Compr Canc Netw 2018; 16: 807-821.

Robichaux JP, Elamin YY, Tan Z, et al. Mechanisms and clinical activity of an EGFR and HER2 exon 20-selective kinase inhibitor in non-small cell lung cancer. Nat Med 2018; 24: 638-646.

Nagano M, Kohsaka S, Ueno $\mathrm{T}$, et al. High-throughput functional evaluation of variants of unknown significance in ERBB2. Clin Cancer Res 2018; 24: 5112-5122.

Hainsworth JD, Meric-Bernstam F, Swanton C, et al. Targeted therapy for advanced solid tumors on the basis of molecular profiles: results from MyPathway, an open-label, phase Ila multiple basket study. J Clin Oncol 2018; 36: 536-542.

Li BT, Shen R, Buonocore D, et al. Ado-trastuzumab emtansine for patients with HER2-mutant lung cancers: results from a phase II basket trial. J Clin Oncol 2018; 36: 2532-2537. HER2-mutated metastatic non-small cell lung cancer (NSCLC): interim results of DESTINY-Lung01. J Clin Oncol 2020; 38: 9504.

Hanna N, Johnson D, Temin S, et al. Systemic therapy for stage IV non-small-cell lung cancer: American Society of Clinical Oncology Clinical Practice Guideline update. J Clin Oncol 2017; 35: 3484-3515.

Planchard D, Popat S, Kerr K, et al. Metastatic non-small cell lung cancer: ESMO Clinical Practice Guidelines for diagnosis, treatment and follow-up. Ann Oncol 2018; 29: Suppl. 4, iv192-iv237.

Dykewicz CA, Centers for Disease Control and Prevention (U.S.), Infectious Diseases Society of America, et al. Summary of the guidelines for preventing opportunistic infections among hematopoietic stem cell transplant recipients. Clin Infect Dis 2001; 33: 139-144.

Pennell NA, Arcila ME, Gandara DR, et al. Biomarker testing for patients with advanced non-small cell lung cancer: real-world issues and tough choices. Am Soc Clin Oncol Educ Book 2019; 39: 531-542.

Heitzer E, Haque IS, Roberts CES, et al. Current and future perspectives of liquid biopsies in genomics-driven oncology. Nat Rev Genet 2019; 20: 71-88.

Melosky B, Popat S, Gandara DR. An evolving algorithm to select and sequence therapies in EGFR mutation-positive NSCLC: a strategic approach. Clin Lung Cancer 2018; 19: 42-50.

Rolfo C, Mack PC, Scagliotti GV, et al. Liquid biopsy for advanced non-small cell lung cancer (NSCLC): a statement paper from the IASLC. J Thorac Oncol 2018; 13: 1248-1268.

Cohen JD, Li L, Wang Y, et al. Detection and localization of surgically resectable cancers with a multi-analyte blood test. Science 2018; 359: 926-930.

Cescon DW, Bratman SV, Chan SM, et al. Circulating tumor DNA and liquid biopsy in oncology. Nat Cancer 2020; 1: 276-290.

(1) Komatsubara KM, Oxnard GR. Application of plasma genotyping technologies in non-small cell lung cancer: a practical review. J Thorac Oncol 2017; 12: 1344-1356.

Diehl F, Schmidt K, Choti MA, et al. Circulating mutant DNA to assess tumor dynamics. Nat Med 2008; 14: 985-990.

Jahr S, Hentze H, Englisch S, et al. DNA fragments in the blood plasma of cancer patients: quantitations and evidence for their origin from apoptotic and necrotic cells. Cancer Res 2001; 61: 1659-1665.

Sacher AG, Paweletz C, Dahlberg SE, et al. Prospective validation of rapid plasma genotyping for the detection of EGFR and KRAS mutations in advanced lung cancer. JAMA Oncol 2016; 2: 1014-1022.

Bettegowda C, Sausen M, Leary RJ, et al. Detection of circulating tumor DNA in early- and late-stage human malignancies. Sci Transl Med 2014; 6: 224ra24.

Oxnard GR, Thress KS, Alden RS, et al. Association between plasma genotyping and outcomes of treatment with osimertinib (AZD9291) in advanced non-small-cell lung cancer. J Clin Oncol 2016; 34: 3375-3382.

Oxnard GR, Paweletz CP, Kuang Y, et al. Noninvasive detection of response and resistance in EGFR-mutan lung cancer using quantitative next-generation genotyping of cell-free plasma DNA. Clin Cancer Res 2014; 20: 1698-1705.

89 Papadimitrakopoulou VA, Han J-Y, Ahn M-J, et al. Epidermal growth factor receptor mutation analysis in tissue and plasma from the AURA3 trial: osimertinib versus platinum-pemetrexed for T790M mutation-positive advanced non-small cell lung cancer. Cancer 2020; 126: 373-380.

Leighl NB, Page RD, Raymond VM, et al. Clinical utility of comprehensive cell-free DNA analysis to identify genomic biomarkers in patients with newly diagnosed metastatic non-small cell lung cancer. Clin Cancer Res 2019; 25: 4691-4700. 
191 Hoffmann-La Roche. A Phase II/III Multicenter Study Evaluating the Efficacy and Safety of Multiple Targeted Therapies as Treatments for Patients With Advanced or Metastatic Non-Small Cell Lung Cancer (NSCLC) Harboring Actionable Somatic Mutations Detected in Blood (B-FAST: Blood-First Assay Screening Trial). www.clinicaltrials.gov/ct2/show/NCT03178552 Date last accessed: 13 August 2020. Date last updated: 16 February 2021.

192 Husain H, Melnikova VO, Kosco K, et al. Monitoring daily dynamics of early tumor response to targeted therapy by detecting circulating tumor DNA in urine. Clin Cancer Res 2017; 23: 4716-4723.

193 Lee JS, Hur JY, Kim IA, et al. Liquid biopsy using the supernatant of a pleural effusion for EGFR genotyping in pulmonary adenocarcinoma patients: a comparison between cell-free DNA and extracellular vesicle-derived DNA. BMC Cancer 2018; 18: 1236.

194 Chang S, Hur JY, Choi Y-L, et al. Current status and future perspectives of liquid biopsy in non-small cell lung cancer. J Pathol Transl Med 2020; 54: 204-212.

195 Thress KS, Paweletz CP, Felip E, et al. Acquired EGFR C797S mutation mediates resistance to AZD9291 in non-small cell lung cancer harboring EGFR T790M. Nat Med 2015; 21: 560-562.

196 Chabon JJ, Simmons AD, Lovejoy AF, et al. Circulating tumour DNA profiling reveals heterogeneity of EGFR inhibitor resistance mechanisms in lung cancer patients. Nat Commun 2016; 7: 11815.

197 Bennouna J, Girard N, Audigier-Valette C, et al. Phase II study evaluating the mechanisms of resistance on tumor tissue and liquid biopsy in patients with EGFR-mutated non-pretreated advanced lung cancer receiving osimertinib until and beyond radiologic progression: the MELROSE trial. Clin Lung Cancer 2020; 21: e10-e14.

198 Offin M, Chan JM, Tenet M, et al. Concurrent RB1 and TP53 alterations define a subset of EGFR-mutant lung cancers at risk for histologic transformation and inferior clinical outcomes. J Thorac Oncol 2019; 14: 1784-1793.

199 Gainor JF, Dardaei L, Yoda S, et al. Molecular mechanisms of resistance to first- and second-generation ALK inhibitors in ALK-rearranged lung cancer. Cancer Discov 2016; 6: 1118-1133.

200 Katayama R, Friboulet L, Koike S, et al. Two novel ALK mutations mediate acquired resistance to the next-generation ALK inhibitor alectinib. Clin Cancer Res 2014; 20: 5686-5696.

201 Pailler E, Faugeroux V, Oulhen M, et al. Acquired resistance mutations to ALK inhibitors identified by single circulating tumor cell sequencing in ALK-rearranged non-small-cell lung cancer. Clin Cancer Res 2019; 25: 6671-6682.

202 Siena S, Bardelli A, Sartore-Bianchi A, et al. Exploiting clonal evolution and liquid biopsy to overcome resistance to anti-EGFR treatment in metastatic colorectal cancer: the CHRONOS trial. Mol Cancer Ther 2018; 17: Suppl. 1, A089.

203 Ortiz-Cuaran S, Mezquita L, Swalduz A, et al. MA21.07 circulating tumor dna analysis depicts potential mechanisms of resistance to BRAF-targeted therapies in $\mathrm{BRAF}^{+}$non-small cell lung cancer. $J$ Thorac Oncol 2019; 14: S337.

204 Mok T, Wu Y-L, Lee JS, et al. Detection and dynamic changes of EGFR mutations from circulating tumor DNA as a predictor of survival outcomes in NSCLC patients treated with first-line intercalated erlotinib and chemotherapy. Clin Cancer Res 2015; 21: 3196-3203.

205 Thress KS, Markovets A, Barrett JC, et al. Complete clearance of plasma EGFR mutations as a predictor of outcome on osimertinib in the AURA trial. J Clin Oncol 2017; 35: 9018.

206 Remon J, Menis J, Hasan B, et al. The APPLE trial: Feasibility and Activity of AZD9291 (Osimertinib) Treatment on Positive PLasma T790M in EGFR-mutant NSCLC Patients. EORTC 1613. Clin Lung Cancer 2017; 18: 583-588.

207 Gray JE, Okamoto I, Sriuranpong V, et al. Tissue and plasma EGFR mutation analysis in the FLAURA trial: osimertinib versus comparator EGFR tyrosine kinase inhibitor as first-line treatment in patients with EGFR-mutated advanced non-small cell lung cancer. Clin Cancer Res 2019; 25: 6644-6652.

208 Abbosh C, Birkbak NJ, Wilson GA, et al. Phylogenetic ctDNA analysis depicts early-stage lung cancer evolution. Nature 2017; 545: 446-451.

209 University of California, San Fransisco. Biomarkers for Risk Stratification in Lung Cancer. www.clinicaltrials. gov/ct2/show/NCT03774758 Date last accessed: 16 August 2020. Date last updated: 17 June 2020.

210 Powrózek T, Krawczyk P, Kucharczyk T, et al. Septin 9 promoter region methylation in free circulating DNA potential role in noninvasive diagnosis of lung cancer: preliminary report. Med Oncol 2014; 31: 917.

211 Ma J, Lin Y, Zhan M, et al. Differential miRNA expressions in peripheral blood mononuclear cells for diagnosis of lung cancer. Lab Invest 2015; 95: 1197-1206.

212 Cazzoli R, Buttitta F, Di Nicola M, et al. microRNAs derived from circulating exosomes as noninvasive biomarkers for screening and diagnosing lung cancer. J Thorac Oncol 2013; 8: 1156-1162.

213 Weiss GJ, Beck J, Braun DP, et al. Tumor cell-free DNA copy number instability predicts therapeutic response to immunotherapy. Clin Cancer Res 2017; 23: 5074-5081.

214 Mazel M, Jacot W, Pantel K, et al. Frequent expression of PD-L1 on circulating breast cancer cells. Mol Oncol 2015; 9: 1773-1782. 
215 Ricklefs FL, Alayo Q, Krenzlin H, et al. Immune evasion mediated by PD-L1 on glioblastoma-derived extracellular vesicles. Sci Adv 2018; 4: eaar2766.

216 Khagi Y, Goodman AM, Daniels GA, et al. Hypermutated circulating tumor DNA: correlation with response to checkpoint inhibitor-based immunotherapy. Clin Cancer Res 2017; 23: 5729-5736.

217 Gandara DR, Paul SM, Kowanetz M, et al. Blood-based tumor mutational burden as a predictor of clinical benefit in non-small-cell lung cancer patients treated with atezolizumab. Nat Med 2018; 24: 1441-1448.

218 Wang Z, Duan J, Cai S, et al. Assessment of blood tumor mutational burden as a potential biomarker for immunotherapy in patients with non-small cell lung cancer with use of a next-generation sequencing cancer gene panel. JAMA Oncol 2019; 5: 696-702.

219 Bratman SV, Yang SYC, lafolla MAJ, et al. Personalized circulating tumor DNA analysis as a predictive biomarker in solid tumor patients treated with pembrolizumab. Nat Cancer 2020; 1: 873-881.

220 Kuziora MA, Higgs BW, Brohawn P, et al. Circulating tumor DNA (ctDNA) variant allele frequencies are reduced in responders to durvalumab and low baseline variant allele frequencies are associated with improved overall survival in NSCLC patients. Cancer Res 2017; 77: Suppl. 13, 582. 